\title{
Terrestrial Influence on the Annual Cycle of the Atlantic ITCZ in an AGCM Coupled to a Slab Ocean Model*
}

\author{
M. Biasutti, D. S. Battisti, And E. S. SarachiK \\ Department of Atmospheric Sciences, University of Washington, Seattle, Washington
}

(Manuscript received 29 September 2003, in final form 14 July 2004)

\begin{abstract}
An atmospheric GCM coupled to a slab ocean model is used to investigate how temperature and precipitation over South America and Africa affect the annual cycle of the Atlantic ITCZ. The main conclusion of this study is that variations in precipitation and temperature forced by the annual cycle of insolation over the continents are as important as variations in insolation over the ocean and in ocean heat transport convergence in forcing the annual march of the Atlantic ITCZ observed in the control simulation. The processes involved are as follows.

The intensity of precipitation over land affects the stability of the atmosphere over the tropical Atlantic Ocean, and thus modulates the intensity of deep convection and convergence in the ITCZ. Both the imposed changes in land precipitation and the subsequent changes in the strength of the ITCZ drive surface wind anomalies, thereby changing the meridional gradient of SST in proximity of the basic-state ITCZ. Finally, atmosphere-ocean feedbacks cause the ITCZ to be displaced meridionally.

Seasonal changes in surface temperature in the Sahara also have a strong influence on the position of the Atlantic ITCZ. Cold wintertime temperatures produce high surface pressure anomalies over Africa and into the tropical North Atlantic and drive stronger trade winds, which cool the North Atlantic by evaporation. The coupled interactions between the SST, the wind, and the ITCZ intensify the anomalies in the equatorial region, causing the southward displacement of the ITCZ in boreal spring.
\end{abstract}

\section{Introduction}

This is the third in a series of papers aimed at decomposing the annual cycle of precipitation in the tropical Atlantic sector into its constituent elements. In Biasutti et al. (2003, hereafter BBS1) and Biasutti et al. (2004, hereafter BBS2) we have described a set of atmospheric general circulation model (AGCM) experiments that separate the annual cycle at any given location into "locally" and "remotely" forced components. These papers described how the annual cycle over land influences the annual cycle of the Atlantic ITCZ when SST is fixed, and how the annual cycle of SST influences precipitation over the continents, in equatorial Africa and equatorial South America, and in the Sahel.

Our strategy for identifying the influence of SST on the continental annual cycle of temperature and precipitation and the influence of the continents on the

\footnotetext{
* Joint Institute for the Study of the Atmosphere and Oceans (JISAO) Contribution Number 1005.
}

Corresponding author address: Michela Biasutti, LamontDoherty Earth Observatory of Columbia University-Oceanography, 61 Route 9W, P.O. Box 1000, Palisades, NY 10968-8000. E-mail: biasutti@1deo.columbia.edu maritime annual cycle of precipitation was to treat the SST and the insolation boundary conditions as independent forcings. So, for example, the influence of SST on the continental climate was inferred from a simulation in which insolation was kept fixed at March value but SST cycled through the observed climatology: in such an experiment, any annual variations of the continental climate must be solely due to the remote influence of the SST. Similarly, the reverse experiment-in which SST was kept fixed at March value but insolation cycled through the observed climatology-illuminated the influence of continental climate on the oceanic climate in an AGCM.

One limitation of our previous work is obvious: the terrestrial influence on the oceanic climate is artificially constrained by the specification of SST. In this study, we couple a slab ocean model (SOM) to the AGCM so that SST can respond to the terrestrial forcing via thermodynamic processes (i.e., in response to changes in surface heat fluxes), albeit not via ocean dynamics. This is still a strong limitation, especially in the equatorial region, where Ekman transport and upwelling force the annual appearance of the equatorial cold tongue. This study will quantify the first-order effect of ocean dynamics in forcing the annual cycle of SST and of the oceanic ITCZ, but will mostly focus on identifying the mechanisms that are important for the development of 
the annual cycle in the Atlantic in the absence of interactive ocean dynamics. It should primarily be considered another step toward understanding how our fully coupled models work.

Three considerations spur our interest in understanding the mechanisms by which the annual cycle is simulated in an AGCM+SOM model configuration. First, current coupled general circulation models do a poor job at simulating the climate of the Atlantic without using flux adjustments (Davey et al. 2002). In order to identify which processes might be responsible for this failure, it is wise to look at a simpler model that can reproduce the annual cycle of the Atlantic climate and identify the mechanisms controlling the annual cycle in this simplified context. That knowledge can then be a starting point for diagnosing the source of error in more complete coupled models. Second, we anticipate that mechanisms important for the annual cycle in the tropical Atlantic are also relevant to interannual variability (Hastenrath 1984). AGCM+SOM configurations have been widely and successfully used to simulate the Atlantic interannual variability (e.g., Seager et al. 2001; Saravanan and Chang 1999), indicating that any insight on the annual cycle gained from the same configuration might be applicable to the interannual variability problem. Third, understanding the first-order response of the tropical Atlantic sector to large changes in external forcing-such as changes in local insolation-can offer guidance in organizing the climate information in the paleo records from the Atlantic Ocean, Africa, and South America into a cohesive picture.

This paper is organized as follows: Section 2 introduces the model and details the experimental design. Section 3 describes the response of the ITCZ to a prescribed change in continental convective heating. Section 4 describes the remote influence of the annual cycle in land surface temperature and land precipitation on the seasonal cycle of the maritime ITCZ. Section 5 describes the local response of the ITCZ to the annual cycle of insolation over the ocean and the annual cycle of ocean heat transport convergence. Section 6 summarizes the paper, draws a comparison of the response of the tropical Atlantic to local and remote forcings, and discusses the implications of our results.

\section{Experimental design}

We use the Community Climate Model version 3 (CCM3) AGCM at its standard resolution (T42 with 19 vertical levels), coupled in the tropical Atlantic region to a fixed 50-m-depth ocean mixed layer. This configuration allows for thermodynamic atmosphereocean interactions, but no ocean dynamics. A detailed description of the atmospheric model and a comparison of the simulated climate with observations can be found in Kiehl et al. (1998), Hack et al. (1998), and other articles in the same special issue of Journal of Climate (1998, vol. 11, no. 6). Chang et al. (2000) and BBS1 have looked in more detail at how CCM3 simulates the climate of the tropical Atlantic in the uncoupled configuration. Saravanan and Chang (2000) and Chiang et al. (2003), each using a configuration similar to the one used in this study, have shown that CCM3 coupled to a slab ocean model simulates the mean state and the variability of the tropical Atlantic climate fairly well.

The effect of ocean dynamics on the annual cycle of SST is parameterized in the SOM by specifying an annually varying heat flux correction (referred to as the $Q$ flux). The $Q$ flux is derived from an uncoupled simulation that used fixed monthly mean observed SST; it is calculated as the difference between the mixed layer heat content tendency and the heat flux provided by the atmosphere (the sum of turbulent surface fluxes and radiative fluxes). The application of the $Q$ flux can be interpreted as the imposition of the ocean heat transport convergence into the oceanic mixed layer, although in reality it also corrects for biases in the atmospheric fluxes. Note that the $Q$ flux is calculated from monthly mean SST tendency and atmospheric fluxes, and this mean value is then linearly interpolated to obtain the instantaneous values used in the integration. This procedure introduces a small additional bias in the simulated climatology.

We couple CCM3 to the SOM only in the tropical Atlantic region and impose climatological SST elsewhere, smoothing the transition over $10^{\circ}$ of latitude. This configuration permits us to observe the response of the tropical Atlantic to a forcing over Africa and South America, while at the same time minimizes the influence of the midlatitudes and of other oceans on the tropical Atlantic climate.

Tables 1 and 2 give a succint overview of the uncoupled and coupled experiments presented in this paper. A more expansive summary is given in the appendix. Recall that in our effort to decompose the annual cycle of the Atlantic ITCZ into locally forced and re-

TABLE 1. Uncoupled experiments: name, insolation forcing over land, SST boundary conditions, and elevated condensational heating over South America and Africa.

\begin{tabular}{llll}
\hline \hline \multicolumn{1}{c}{ Name } & \multicolumn{1}{c}{ Insolation over land } & \multicolumn{1}{c}{ SST } & Land condensational heating \\
\hline CTL (Control) & Climatological & Climatological & Calculated (=Climat) \\
PM (Perpetual Mar) & Vernal equinox (21 Mar) & Mar & Calculated ( Mar) \\
PMS (Perpetual Mar SST) & Climatological & Mar & Calculated ( Climat) \\
PMJQ (Perpetual Mar with Jun heating) & Vernal equinox (21 Mar) & Mar & Prescribed (=Jun) \\
LPVE (Perpetual vernal equinox over land) & Vernal equinox (21 Mar) & Climatological & Calculated ( Mar) \\
\hline
\end{tabular}


TABLE 2. Coupled experiments: name, insolation forcing over land, $Q$ flux, and elevated condensational heating over South America and Africa.

\begin{tabular}{|c|c|c|c|c|}
\hline Name & Land insolation & Ocean insolation & $Q$ flux & Land condensational heating \\
\hline CpldCTL & Climatological & Climatological & Climatological & Calculated (=Climat) \\
\hline CpldPJQ & Climatological & Climatological & Climatological & Prescribed (= Jun) \\
\hline CpldPMQ & Climatological & Climatological & Climatological & Prescribed (= Mar) \\
\hline CpldLPVE & Vernal equinox (21 Mar) & Climatological & Climatological & Calculated ( $\sim$ Mar) \\
\hline CpldLPVE $\overline{Q f l u x}$ & Vernal equinox (21 Mar) & Climatological & Annual mean & Calculated ( $\sim$ Climat $)$ \\
\hline CpldLOPVE & Vernal equinox (21 Mar) & Vernal equinox (21 Mar) & Climatological & Calculated ( Mar) \\
\hline
\end{tabular}

motely forced processes, we treat the ocean forcings and the land forcings as independent. Accordingly, our simulations are distinguished by independently considering the annual cycle of insolation over land, SST (for the uncoupled simulations), and insolation over the ocean and $Q$ flux (for the coupled simulations).

In most simulations the elevated condensation heating is calculated by the convective parameterization in CCM3. However, in selected simulations (see Tables 1 and 2 and the appendix), we have discarded the condensation heating over Africa and South America calculated by the model and instead prescribed a constant value (obtained from a previous simulation corresponding to either June or March insolation values). By prescribing the continental condensation heating, we decouple continental convection from continental surface temperature and can observe the response of the ocean to each forcing separately.

In the following sections we will show differences between a control simulation, in which insolation and ocean $Q$ flux vary climatologically, and simulations in which the annual cycle has been totally or partially suppressed over either the landmasses or the oceans. For example, the difference between the control simulation and an experiment with perpetual boreal vernal equinox insolation over land (coupled control minus coupled land perpetual vernal equinox, CpldCTLCpldLPVE) shows the ocean response to the annual cycle over land induced by insolation. Similarly, the difference between the control simulation and an experiment with climatological insolation and $Q$ flux but prescribed fixed elevated condensation heating over Africa and South America (coupled control minus coupled perpetual March heating, CpldCTL-CpldPMQ) shows the ocean response to the annual cycle of precipitation over land, in the absence of an annual cycle of land surface temperature.

In the rest of the paper we will briefly reintroduce our experiments and explain how we interpret the differences among them. The reader is directed to Tables 1 and 2 and the appendix for a comprehensive reference to all the experiments and the differences in the applied forcings that distinguish them.

All simulations that have an annual cycle in the forcing were run for at least 12 years; the first 4 years were discarded, and the analysis was conducted on the average of the remaining years. Simulations in which all forcings were kept constant were run for 12 months.

\section{The ITCZ response to a steady continental forcing}

When SST is prescribed underneath an AGCM, the response of the simulated oceanic ITCZ to annual changes in insolation over the adjacent continents is a change in intensity, but not in position (BBS1). Sensitivity experiments forced by continental elevated heating (and analyzed in detail in BBS2) suggest that, in uncoupled simulations, continental precipitation modulates the intensity of maritime precipitation. The insolation-induced changes in continental convection drive changes in the stability (temperature) of the free troposphere throughout the tropical Atlantic, and thus affect the intensity of convection; the changes in land surface temperature do not appreciably affect the oceanic precipitation directly (BBS2). What is the response of the ITCZ to continental forcings when we expand our model to include thermodynamic atmosphereocean interactions? What other mechanisms come into play? We approach this question in steps: First, we investigate the response of the Atlantic SST and ITCZ to a steady elevated condensation heating imposed over South America and Africa (this section). Second, we show the maritime response to insolation-induced annual variations in land surface temperature and precipitation over the continents (section 4).

Figure 1 shows the forcing applied in all experiments described in this section. The imposed forcing is the difference in condensation heating over South America and Africa between the months of June and March [as simulated by CCM3 in an experiment with prescribed March SST and climatologically varying insolation, denoted in BBS1 by perpetual March SST (PMS)]. Figure 1a shows the horizontal pattern of the heating difference at $500 \mathrm{mb}$; Fig. 1b shows the vertical profile of the heating difference averaged over South America.

Figure $2 \mathrm{a}$ shows the oceanic response in precipitation and surface winds to the forcing shown in Fig. 1 in an uncoupled simulation with March SST and insolation conditions (we also performed a similar set of simulations, but with September conditions, which supports the conclusions drawn in this section). Specifically, Fig. 

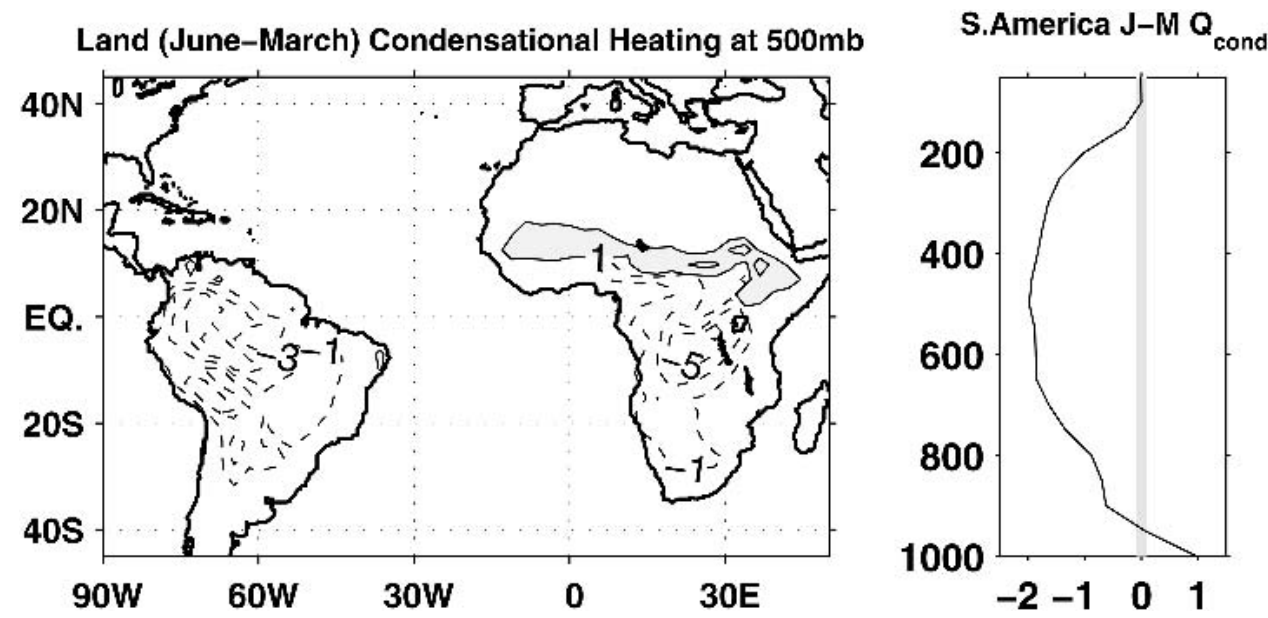

Fig. 1. The Jun-Mar difference in condensational heating over South America and Africa, taken from a simulation with perpetual Mar SST and climatologically varying insolation over land. (a) Heating difference at $500 \mathrm{mb}$. The contour interval is $2 \times 10^{-5} \mathrm{~K} \mathrm{~s}^{-1}$, starting with $\pm 10^{-5}$. Negative contours are dashed, the zero line is omitted, shading indicates values larger than $10^{-5} \mathrm{~K} \mathrm{~s}^{-1}$. (b) Vertical profile as a function of pressure $(\mathrm{mb})$ of the heating difference averaged over South America (in units of $10^{-5} \mathrm{~K} \mathrm{~s}^{-1}$ ).

2a shows the "PMJQ minus PM" difference, where PM simulates a perpetual March and PMJQ simulates a perpetual March with imposed June condensation heating over the continents. The mechanisms responsible for the uncoupled response have been described in BBS2 and can be summarized as follows. A prescribed negative heating over the continents causes a cooling of the free troposphere that is spread horizontally by the atmospheric circulation, thereby changing the stability profile of the atmosphere everywhere in the Tropics outside the area of prescribed heating. In the Atlantic ITCZ region, CAPE is enhanced and precipitation becomes more vigorous. In regions that are nonconvective in the basic state, the change in stability is not sufficient to induce deep convection, and thus the precipitation response is muted outside of the ITCZ region.

Figures $2 \mathrm{a}$ and $2 \mathrm{~b}$ show that the surface wind response is more intense near the equator and to the southern edge of the precipitation anomalies. The analysis of sensitivity experiments (not shown) in which the elevated heating is applied only in South Africa or only in South America suggests that the wind anomalies shown in Fig. 2a should be interpreted as mostly due to both the Rossby wave response to African heating and the feedback associated with changes in the ITCZ itself; the wind response to South American heating is small by comparison.

How does the coupling affect the ITCZ response? Figure $2 b$ shows the difference in precipitation and surface winds between the CpldPJQ and CpldPMQ simulations, that is, between coupled AGCM+SOM simulations in which condensation heating over Africa and South America is prescribed to be fixed at the June and March values, respectively, but otherwise the climate is forced by the annual cycle of insolation and $Q$ flux. Therefore, the difference "CpldPJQ minus CpldPMQ" is due to the difference in the continental condensation heating shown in Fig. 1, but the coupled simulations have an annual cycle in their basic state. Figure $2 b$ shows the CpldPJQ-CpldPMQ difference during March, to be compared with Fig. 2a.

As in the uncoupled case, when continental precipitation is decreased, the intensity of precipitation in the ITCZ is enhanced (by roughly $20 \%$, when averaged over the whole ITCZ). However, the coupled response is drastically different from the uncoupled response in that, in the coupled case, the ITCZ has shifted $7^{\circ}$ northward in response to the imposed continental condensation heating anomalies. This suggests that precipitation over the African and South American landmasses has the ability to affect the annual meridional march of the ITCZ.

The northward shift of the ITCZ could have been anticipated in light of the surface wind response in the uncoupled case (Fig. 2a): the southeasterly trades to the south of the ITCZ are anomalously strengthened in response to the continental forcing. Stronger winds mean stronger evaporation and latent heat loss from the ocean. When a slab ocean model is coupled to the AGCM, this anomalous latent heat flux cools the SST to the south of the mean ITCZ, establishing a crossequatorial gradient that "pushes" the ITCZ northward. Associated with the SST gradient and the ITCZ shift is an enhanced meridional wind response (cf. Figs. $2 b$ with 2a). The mechanisms by which the surface wind, and thus the surface convergence and the ITCZ, are thought to respond to a meridional SST gradient anomaly have been described, for example, by Lindzen and Nigam (1987) and Hastenrath and Greischar 


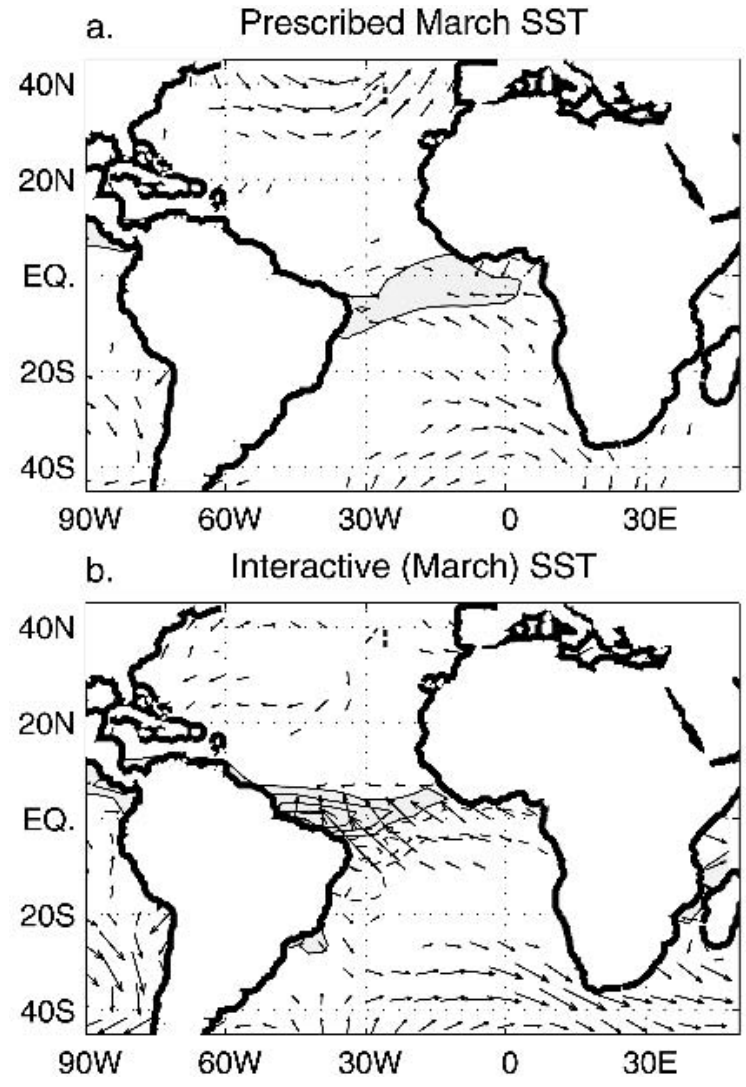

FIG. 2. The surface wind and ITCZ response forced over the ocean by the constant condensational heating anomalies shown in Fig. 1. In experiments with prescribed SST, the response of the Atlantic ITCZ is more intense precipitation, and the wind response is concentrated to the south of the ITCZ. In experiments with interactive SST, the ITCZ is both more intense (by about $20 \%$ ) and shifted to the north. Associated with the northward shift of the ITCZ is a strong southerly wind anomaly. (a) Perpetual Mar with Jun continental elevated heating minus perpetual Mar (PMw/JQ - PM). (b) Perpetual Jun continental elevated heating expt minus perpetual Mar continental elevated heating expt (CpldPJQ - CpldPMQ) for Mar insolation and SST conditions. The contour interval is $4 \mathrm{~mm} \mathrm{day}^{-1}$, starting with the \pm 2 contour, negative contours are dashed, the zero line is omitted, shading denotes anomalies larger than $2 \mathrm{~mm} \mathrm{day}^{-1}$, and only wind anomalies larger than $1 \mathrm{~m} \mathrm{~s}^{-1}$ are plotted. Anomalies over land have been masked out

(1993). Very briefly, SST anomalies are communicated by turbulent mixing to the boundary layer, thus creating a low-level anomaly in pressure, wind, and convergence. This model works quite well in regions of strong gradients, but surface winds and convergence are also influenced by the free troposphere and thus feel the effect of the elevated condensational heating released in the ITCZ itself (McGauley et al. 2004; Chiang et al. 2001; BBS2). Therefore, it is best to think of the SST, the surface wind, and the ITCZ as a coupled system.

Note that over the ocean the wind response to the continental elevated heating forcing of Fig. 1 is comprised of two components: the direct response to con- tinental heating (Gill 1980), which we expect to be constant, and the response to changes in oceanic precipitation, which we expect to depend on the position of the basic-state ITCZ. It follows that a constant anomaly in continental precipitation does not force a constant precipitation anomaly over the ocean but, rather, a constant meridional displacement of the ITCZ from its basic-state annual cycle.

This can be seen in Fig. 3, which shows the annual cycle of the CpldPJQ-CpldPMQ anomalies in precipitation, SST, surface winds and heat flux into the surface ocean in the central Atlantic $\left(30^{\circ} \mathrm{W}\right)$ as a function of month and latitude. Also shown is the annual cycle of the position of the ITCZ (in this case identified by the confluence line) in both runs. The ITCZ in the CpldPJQ run is always about $7^{\circ}$ to the north of that in the CpldPMQ run with the largest displacement of the ITCZ rainfall occurring in boreal spring, the smallest in boreal winter (Fig. 3a). The ITCZ displacement is associated with a positive anomalous meridional SST gradient and wind anomalies that maximize to the north of the CpldPMQ confluence line (Fig. 3b); outside of the region spanned by the annual march of the ITCZ the annual cycle of the anomalies is minimal. A band of strong heat flux anomalies (Fig. 3c) follows the annual march of the ITCZ. (Note that, although in this model SST anomalies can only be generated by heat flux anomalies, the two fields are not in perfect correspondence. The annual mean of the heat flux anomalies is zero by construction, as we are analyzing the equilibrium state; the equilibrium annual mean SST anomalies need not be-and are not-zero.)

Figure 3d shows the CpldPJQ-CpldPMQ anomalies in wind speed squared; because evaporation depends on the square of the wind, the similarity in the patterns in Figs. 3c and 3d suggests that heat flux anomalies can be explained by wind-induced anomalies in evaporation (a larger wind speed means more evaporation and a cooling of the ocean). A decomposition of the total heat flux anomalies confirms that the wind-induced latent heat flux anomalies are the dominant component of the strong heat flux anomalies in the equatorial region, although radiative flux anomalies (not shown) are also nonnegligible. This finding supports our original supposition: the marked annual cycle in the response of SST to a steady continental forcing is due to the fact that wind changes depend on the basic-state ITCZ.

To summarize, a reduction in continental precipitation induces a remote cooling of the free troposphere and a reduction in stability. In the ITCZ, this translates in more active deep convection and larger low-level convergence. The surface wind anomalies (generated in response to both the prescribed elevated heating over land and the precipitation changes in the ITCZ) induce a cooling to the south of the mean ITCZ (Figs. 2a,b). Finally, SST, surface wind, and oceanic precipitation adjust to each other in an interactive way, establishing the anomalies portrayed in Figs. $2 \mathrm{~b}$ and 3 . A constant 
a.
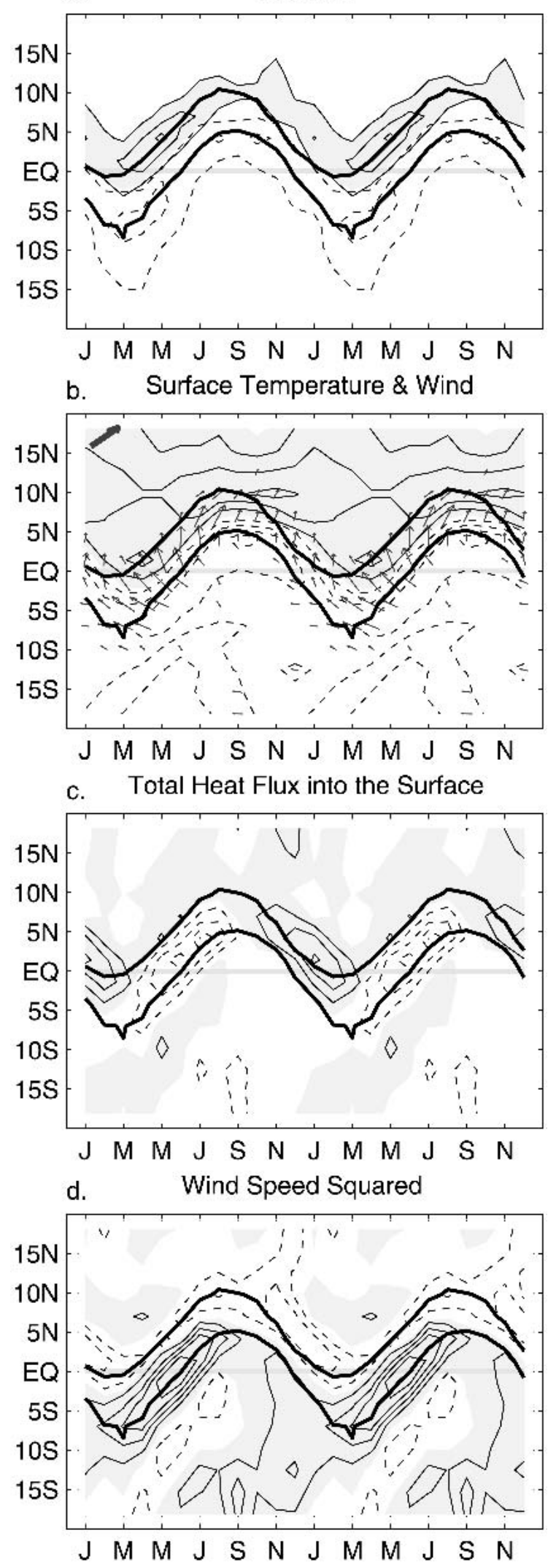

anomaly in continental precipitation forces a nearly constant meridional displacement of the ITCZ from its basic-state annual cycle.

\section{The ITCZ response to an annually varying continental forcing}

\section{a. Response to insolation-induced changes in land surface temperature and precipitation}

In this section we present the response of the Atlantic ITCZ to annually varying forcing from the continents. Specifically, we compare two simulations: a control run, with climatologically varying insolation and $Q$ flux, and an experiment in which insolation over land is fixed at the boreal vernal equinox, while insolation over the ocean and the $Q$ flux vary climatologically. The difference between the two simulations is the response to the top-of-the-atmosphere insolation differences shown in Fig. 4. It can be thought of as the response to the annual cycle of insolation over land.

Before presenting the results of the coupled experiments, we will review the analogous uncoupled experiments (i.e., with prescribed SST). Figures 5a, 5c, 5e, and $5 \mathrm{~g}$ show the difference between the uncoupled CTL simulation and the uncoupled LPVE simulation (forced with perpetual vernal equinox insolation over land) during March, June, September, and December. Thus, the precipitation anomalies shown in Fig. 5 (left) are forced by the corresponding difference in insolation over land from the equinox value (Fig. 4) and are somewhat modified by soil processes, which hold memory of the forcing from one month to the next (BBS1). Figures $5 \mathrm{a}, 5 \mathrm{c}, 5 \mathrm{e}$, and $5 \mathrm{~g}$ present a companion view of the insolation-induced anomalies that were presented in BBS1 (cf. Fig. 10 of that paper). The left column of Fig. 5 shows that, over land, to zero order precipitation increases with increasing insolation and that, over the ocean, the intensity of the ITCZ is sensitive to conti-

$\leftarrow$

FIG. 3. The annual cycle of the response of the central Atlantic $\left(30^{\circ} \mathrm{W}\right)$ to the forcing in land condensational heating shown in Fig. 1 , as a function of month and latitude [perpetual Jun continental elevated heating minus perpetual Mar continental elevated heating (CpldPJQ - CpldPMQ)]. (a) CpldPJQ - CpldPMQ precipitation anomalies (contour interval of $4 \mathrm{~mm} \mathrm{day}^{-1}$, starting with \pm 2 ). (b) CpldPJQ - CpldPMQ SST anomalies (contour interval of $0.5^{\circ} \mathrm{C}$; the zero line is omitted) and surface wind anomalies (only wind anomalies larger than $2 \mathrm{~m} \mathrm{~s}^{-1}$ are plotted; the bold arrow in the upper-left corner corresponds to a $10 \mathrm{~m} \mathrm{~s}^{-1}$ wind velocity). (c) CpldPJQ - CpldPMQ total heat flux anomalies into the ocean (contour interval of $30 \mathrm{~W} \mathrm{~m}^{-2}$; the zero line is omitted). (d) CpldPJQ - CpldPMQ wind speed squared anomalies (contour interval of $16 \mathrm{~m}^{2} \mathrm{~s}^{-2}$; the zero line is omitted). In every panel the thick lines indicate the climatological position of the confluence line in CpldPJQ (farther to the north) and CpldPMQ (farther to the south), the dashed lines indicate negative values, and the shading indicates (b),(c),(d) positive values or (a) values larger than the value of the first positive contour line. 
a. CTL-LPVE March

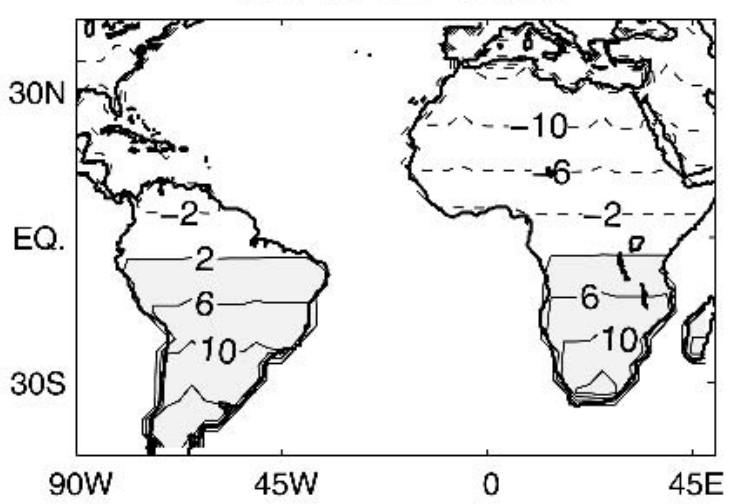

b.

CTL-LPVE June

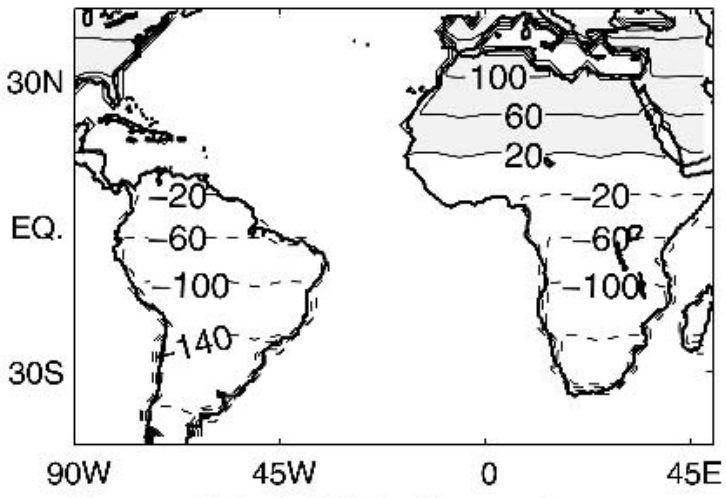

c. CTL-LPVE September

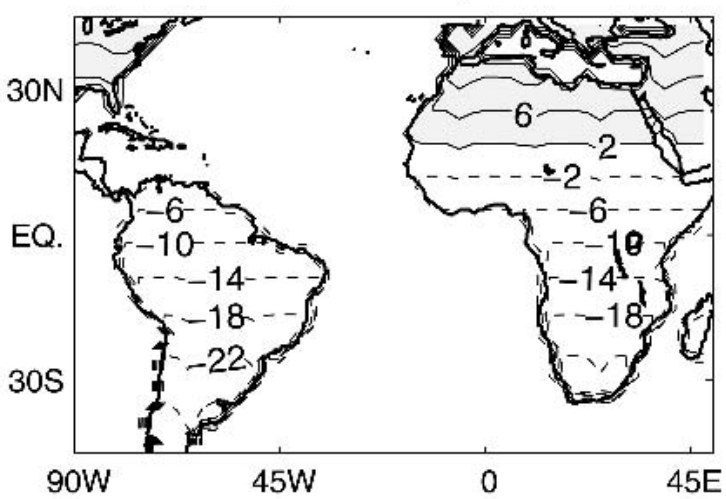

d. CTL-LPVE December

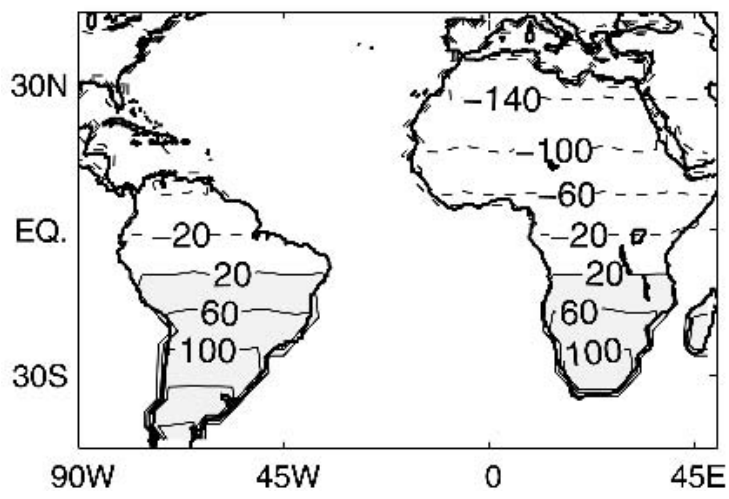

nental forcing, but, when SST are prescribed, the location of the ITCZ hardly changes, at the resolution of these simulations. We have suggested in BBS2, and reviewed in section 3 , that the changes in ITCZ intensity are a response to the changes in the free troposphere stability that accompany changes in continental precipitation. The concomitant changes in land surface temperature do not have a sizable direct effect on oceanic precipitation in the uncoupled experiment (BBS2).

Figures 5b, 5d, 5f, and 5h show the CpldCTLCpldLPVE difference in precipitation during March, June, September, and December. The forcing is the same as that for the uncoupled case (Fig. 4), but now SST is allowed to change in response to changes in turbulent and radiative surface heat fluxes. As expected, the precipitation anomalies over land are very similar to those from the uncoupled case (cf. the left and right columns of Fig. 5). Over the ocean, the precipitation anomalies are similar to those in the uncoupled case during June, September, and December but show a markedly different pattern during March. In the uncoupled case (Fig. 5a), the March anomalies show a slightly weakened ITCZ. In the coupled case (Fig. 5b), the ITCZ is both weakened and shifted farther south in the CpldCTL simulation compared to the CpldLPVE simulation.

Figure 6 provides a better description of the influence that the seasonal cycle in insolation over land has on the seasonal cycle over the tropical ocean. It shows the annual cycle of precipitation and SST in the central Atlantic (at $\left.30^{\circ} \mathrm{W}\right)$ in the CpldCTL and the CpldLPVE simulation. In the control simulation (Fig. 6a), the main ITCZ stays north of $5^{\circ} \mathrm{S}$ and a secondary precipitation center develops during boreal spring at about $10^{\circ} \mathrm{S}$. In the CpldLPVE experiment, in which the annual cycle of both temperature and precipitation over the continents is suppressed (Fig. 6b), the northern ITCZ does not reach as far south, while the southern precipitation develops earlier in the year and is found farther south at about $20^{\circ} \mathrm{S}$. We see, by comparing Figs. $6 \mathrm{a}$ and $6 \mathrm{~b}$, that suppressing the annual cycle over the continents markedly suppresses the annual cycle in the position of the ITCZ.

The mechanisms by which land convective heating can affect the position of the ITCZ have been addressed in section 3. In this section we will focus our description on how continental surface temperatures can affect the ITCZ. We will analyze the CpldCTLCpldLPVE differences, which compound the effect of

$\leftarrow$

FIG. 4. The annual cycle of TOA insolation over land, shown as differences from the (boreal) vernal equinox value. (a) Mar CTL - Mar LPVE. (b) Jun CTL - Jun LPVE. (c) Sep CTL Sep LPVE. (d) Dec CTL - Dec LPVE. The contour interval is 4 $\mathrm{W} \mathrm{m}{ }^{-2}\left(40 \mathrm{~W} \mathrm{~m}^{-2}\right)$, starting with $\pm 2(20)$ in (a) and (c) [(b) and (d)]. The dashed contours indicate negative values and the shading indicates positive values larger than $2 \mathrm{~W} \mathrm{~m}^{-2}\left(20 \mathrm{~W} \mathrm{~m}^{-2}\right)$. 
a. CTL-LPVE March

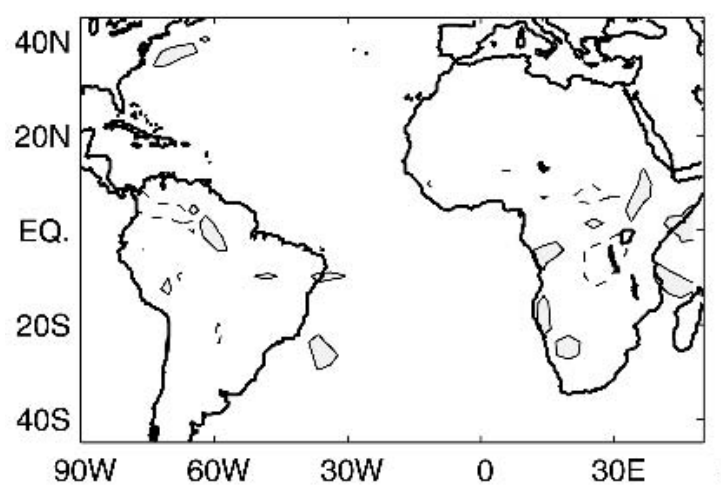

c.

CTL-LPVE June

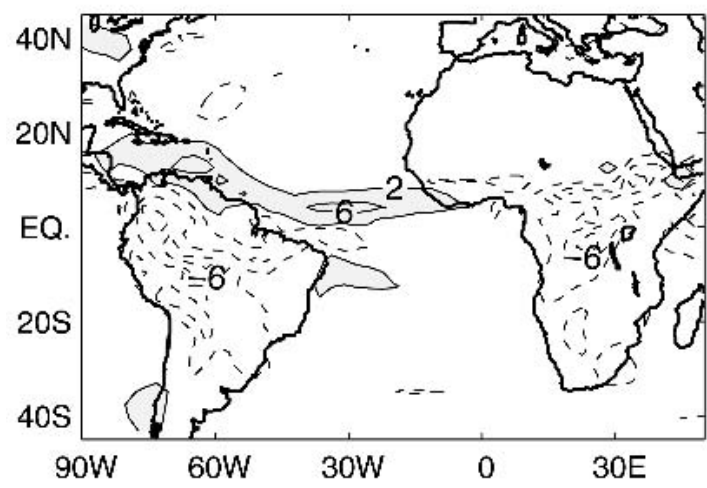

e. CTL-LPVE September

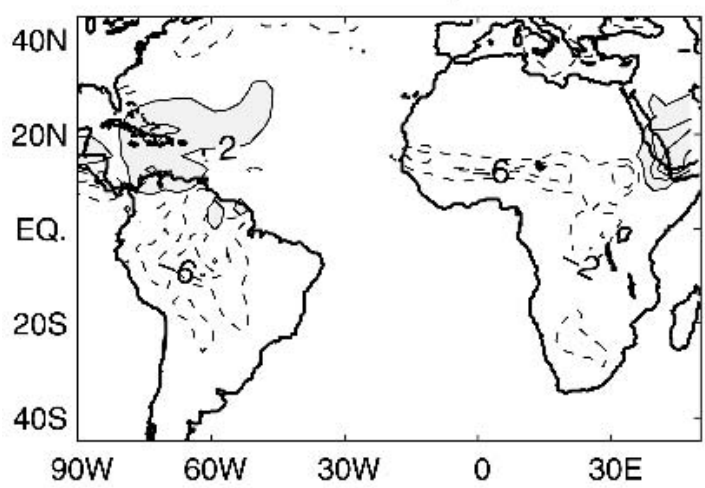

g. CTL-LPVE December

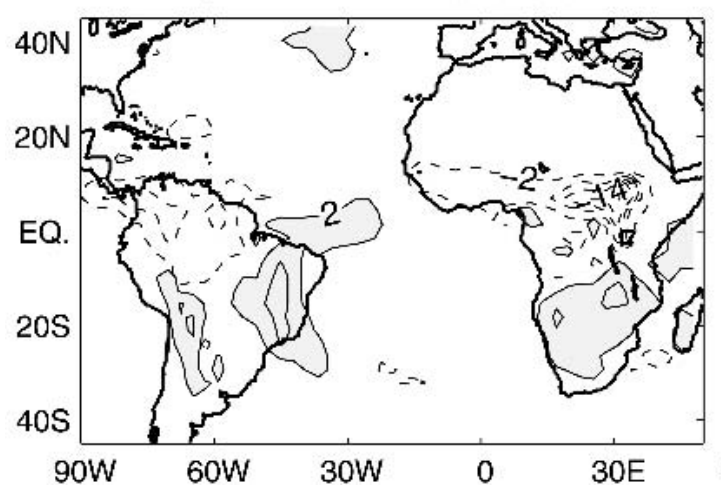

b. CpldCTL-CpldLPVE March

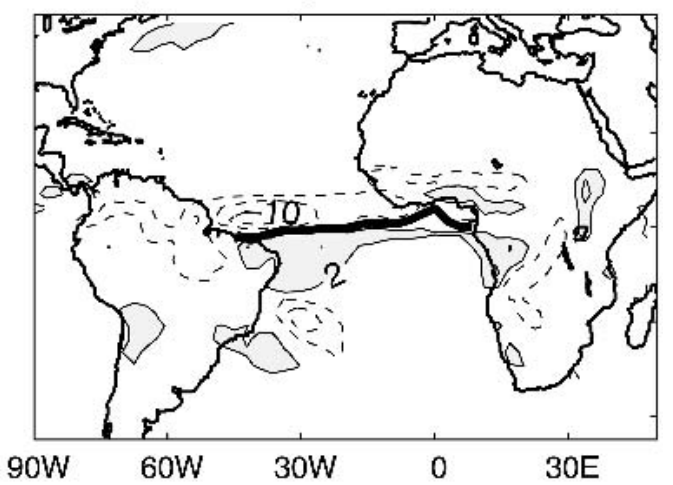

d. CpldCTL-CpldLPVE June

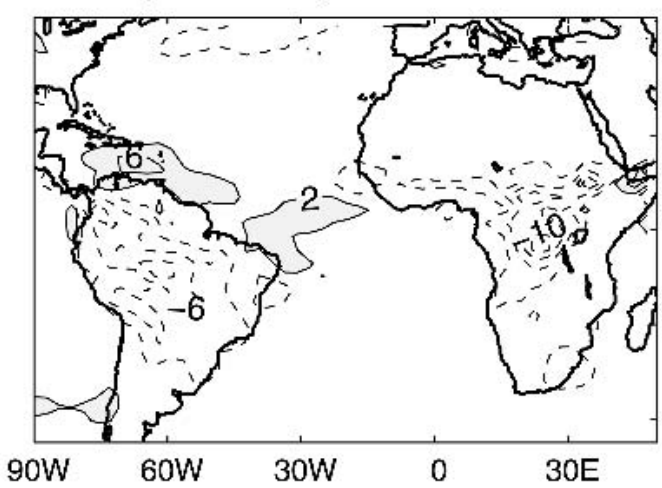

f. CpldCTL-CpldLPVE September

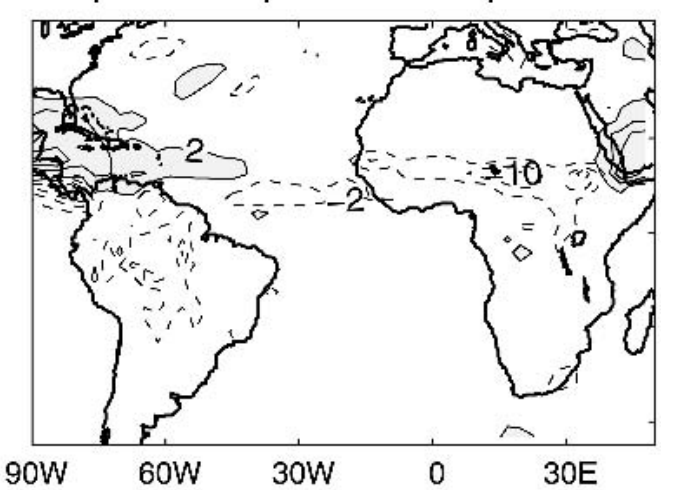

h. CpldCTL-CpldLPVE December

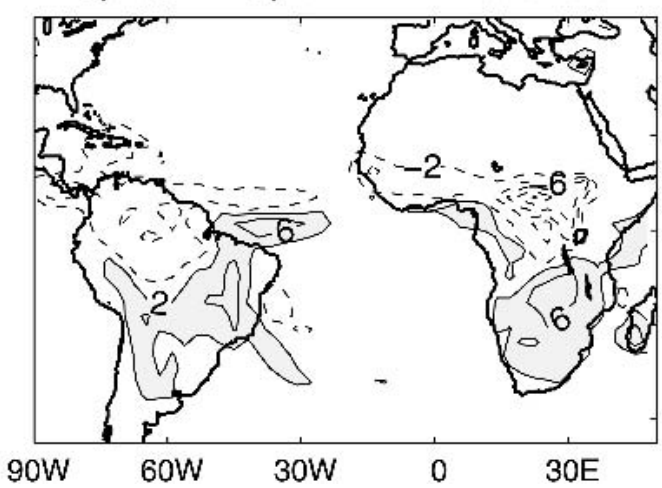


Control

a. PREC CPIdCTL

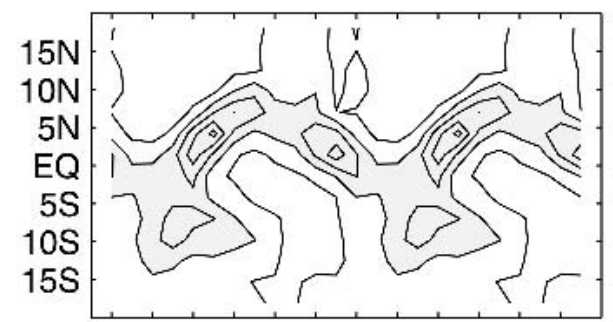

c. SST \& V CpldCTL

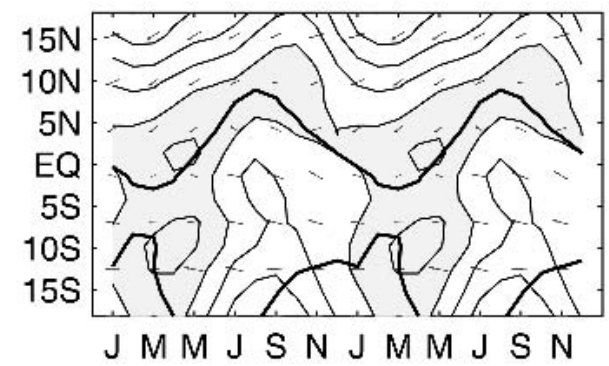

Oceanic Forcings Only

b. PREC CpldLPVE

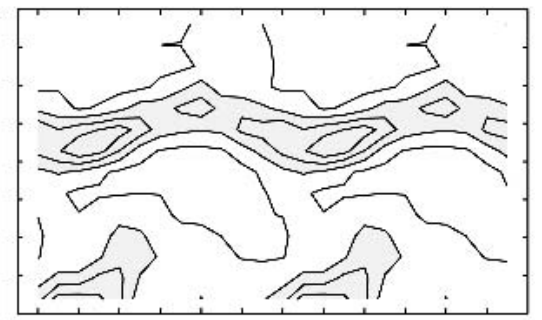

d. SST \& V CpldLPVE

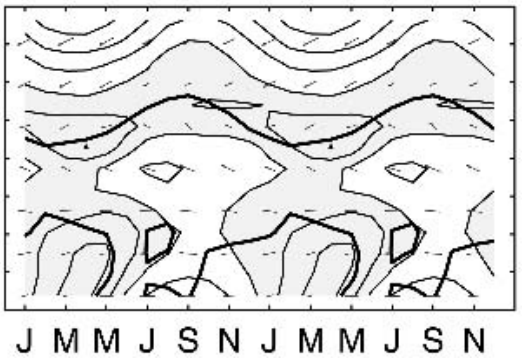

FIG. 6. The annual cycle of precipitation, SST, and surface wind in the central Atlantic $\left(30^{\circ} \mathrm{W}\right)$ in simulations with different annual forcings. (a), (c) CpldCTL: annual cycle due to both local (insolation and $Q$ flux) forcings and remote (land insolation) forcing. (b), (d) CpldLPVE: annual cycle due only to local forcings (insolation and $Q$ flux); the remote forcing coming from the annual cycle over land has been suppressed. The contour interval for precipitation is $3 \mathrm{~mm}$ day $^{-1}$, starting with \pm 1.5 ; values larger than $4.5 \mathrm{~mm} \mathrm{day}^{-1}$ are shaded. The contour interval for SST is $1^{\circ} \mathrm{C}$; values larger than $27^{\circ} \mathrm{C}$ are shaded. Only surface wind vectors larger than $5 \mathrm{~m} \mathrm{~s}^{-1}$ are plotted; the bold arrow in the lower-left corners indicates a $10 \mathrm{~m} \mathrm{~s}^{-1}$ wind speed.

both land elevated heating and land surface temperature, but the effect of temperature is dominant (cf. section $4 \mathrm{~b}$ ) and can be easily isolated in the analysis.

Figure 7 shows the spatial pattern of CpldCTLCpldLPVE surface air temperature (SAT) difference during March over the entire Atlantic sector (over the ocean SAT closely mimics SST). To help locate the precipitation displacement due to continental forcing, we have plotted the zero line in precipitation anomalies from Fig. 5b in Fig. 7. Again, it is clear that the southward displacement of the ITCZ is associated with an anomalous negative meridional gradient of SST (and hence surface air temperature) near the equator. How is this anomalous gradient established?

Figure 8 shows the anomalies in total surface heat flux (Fig. 8a) and latent surface heat flux (Fig. 8b) integrated over December, January, and February. The latent heat flux makes up the bulk of the total heat flux in the equatorial area, but radiative fluxes are also important, especially in the stratus region off the South African coast. The similarities between Figs. 7 and $8 \mathrm{a}$ in the deep Tropics and between Figs. 8a and 8b suggest that wintertime December-February (DJF) latent heat flux anomalies are responsible for the generation of the anomalous equatorial SST gradient during March ${ }^{1}-$ and thus for the shift of the ITCZ. (When comparing

\footnotetext{
${ }^{1} \mathrm{We}$ remark that the anomalous equatorial meridional SST gradient is negligible prior to the DJF season (not shown).
}

$\leftarrow$

FIG. 5. The precipitation response to the annual cycle of TOA insolation over land in the case of (left column) prescribed SST and (right column) interactive SST. The effect of having an interactive SST is to allow the ITCZ to move, as can be easily inferred by comparing the coupled and uncoupled Mar anomalies. (a) Mar CTL - Mar LPVE, (b) Mar CpldCTL - Mar CpldLPVE, (c) Jun CTL - Jun LPVE, (d) Jun CpldCTL - Jun CpldLPVE, (e) Sep CTL - Sep LPVE, (f) Sep CpldCTL - Sep CpldLPVE, (g) Dec CTL - Dec LPVE, (h) Dec CpldCTL - Dec CpldLPVE. The contour interval is $4 \mathrm{~mm}$ day $^{-1}$, starting with \pm 2 ; the dashed contours indicate negative values; and the shading indicates positive values larger than $2 \mathrm{~mm} \mathrm{day}^{-1}$. 


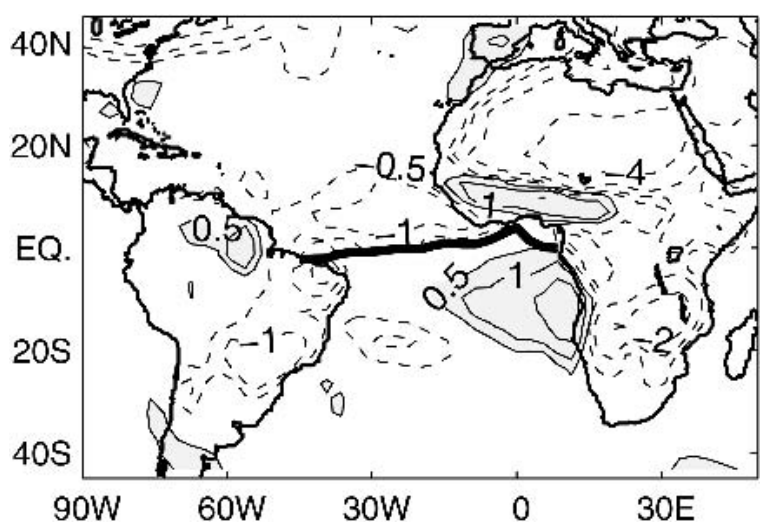

FIG. 7. The surface air temperature response to the annual cycle of insolation over land in the case of interactive SST (Mar CpldCTL - Mar CpldLPVE). The contours are spaced logarithmically: $\pm 0.5^{\circ}, \pm 1^{\circ}, \pm 2^{\circ}, \pm 4^{\circ}, \pm 8^{\circ} \mathrm{C}$; negative values are dashed; and positive values larger than $0.5^{\circ} \mathrm{C}$ are shaded.

Figs. 7 and 8 , recall that poleward of $20^{\circ}$ the calculated SST is linearly merged with the prescribed SST.) Therefore we next focus on how the latent heat flux anomalies are generated.

Figure 9 shows the surface wind and latent heat flux anomalies for each winter month in both the uncoupled and the coupled experiments. We first focus on the coupled results (Fig. 9, right). During December (Fig. $9 \mathrm{~b}$ ) the largest surface latent heating anomalies occur west of the Sahara in the northern tropical Atlantic; at and south of the equator the latent heating anomalies are positive and weaker. A linear analysis, following Saravanan and Chang (2000), indicates that the latent heat flux anomalies are mostly a consequence of wind speed anomalies (latent heat flux anomalies due to changes in air-sea temperature difference are large off the Saharan coast, but increase SST, the opposite of the wind speed effect). The enhanced trades in the northern tropical Atlantic are a consequence of the insolation-induced cold anomalies and high surface pressure over the Sahara (not shown). This conclusion is consistent with our analysis in section $4 \mathrm{~b}$ below, which suggests that, for understanding the seasonal march of the ITCZ, insolation-driven changes in continental temperature are more important than changes in continental convection.

The December latent heat flux anomalies extend to the equatorial region where they force a negative meridional gradient in SST. In January (Fig. 9d), northerly cross-equatorial wind anomalies are in place and cause a strengthening of the meridional dipole in latent heat flux anomalies in the equatorial region. By February (Fig. 9f) the latent heat anomalies off northern Africa have changed sign, while the negative cross-equatorial gradient of SST is maintained, and intensified, by a narrow patch of cross-equatorial wind. A comparison with the uncoupled case (Fig. 9, left) shows that the act of coupling amplifies the cross-equatorial wind and latent heat flux anomalies in the equatorial region (cf. Figs. $9 \mathrm{c}$ and $9 \mathrm{~d}$ and, especially, 9e and 9f). There is a positive feedback between the wind and the SST: the wind-induced latent heat anomalies strengthen the SST gradient, which in turn drives a stronger crossequatorial wind. This wind-evaporation-SST feedback was first introduced in an idealized study of the annual cycle of the ITCZ by Xie and Philander (1994) and later invoked to explain the tropical Atlantic decadal variability (Chang et al. 1997). Nevertheless, we note that the latent heat flux anomalies in the uncoupled case (Figs. 9a,c,e) are by themselves sufficient to induce a negative SST gradient at the equator; in this sense, the wind-evaporation-SST feedback, while undoubtedly an integral part of the development and the maintenance in time of the SST gradient and the displacement
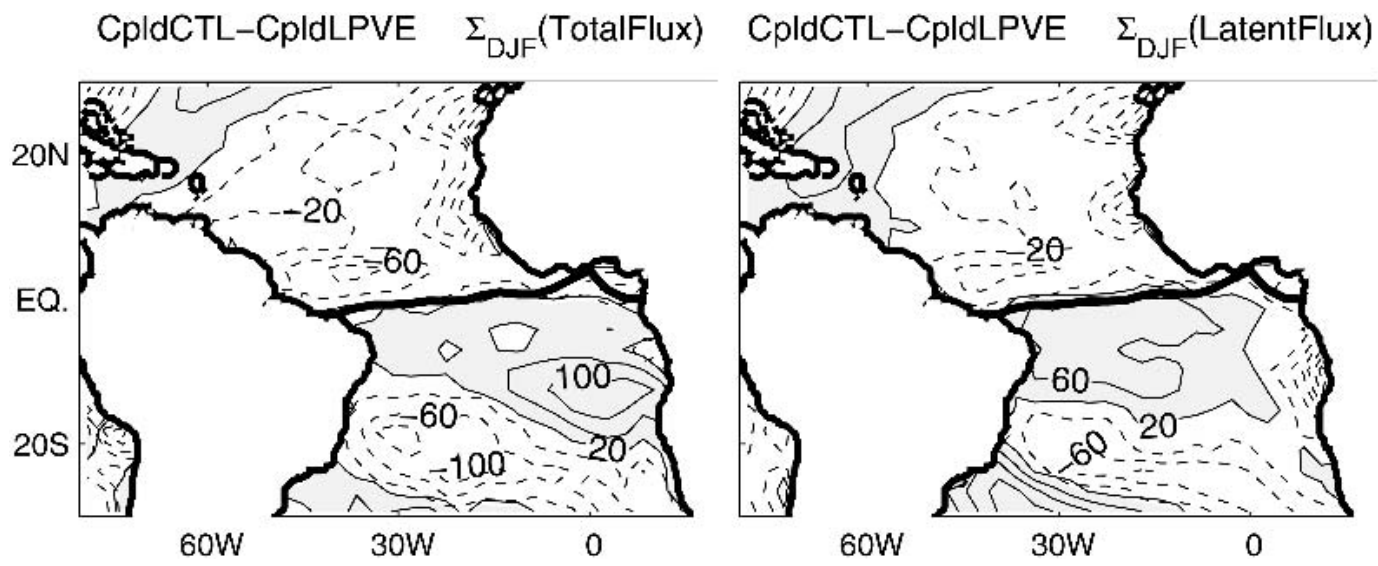

FIG. 8. The wintertime (the sum of Dec, Jan, and Feb) (left) total and (right) latent surface heat flux response to the annual cycle of insolation over land in the case of interactive SST (CpldCTL - CpldLPVE). The contour interval is $40 \mathrm{~W} \mathrm{~m}^{-2}$, starting with \pm 20 . The thick line is the zero line of the Mar CpldCTL - Mar CpldLPVE precipitation anomalies. 
a. CTL-LPVE Dec LHFLX \& $\mathrm{V}_{\mathrm{sfc}}$

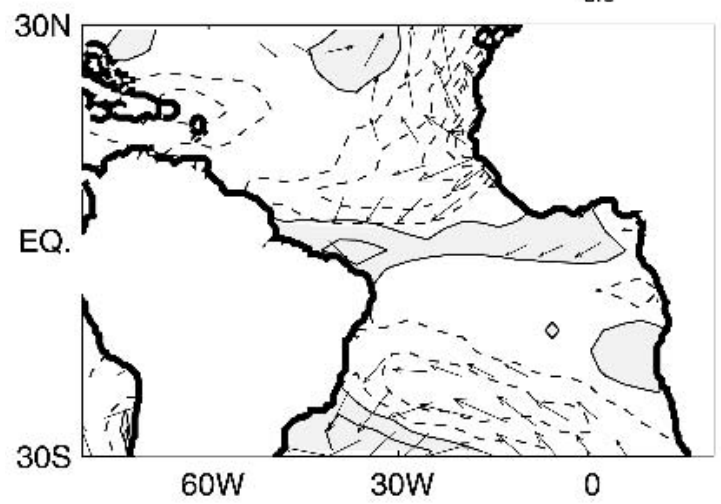

c. CTL-LPVE Jan LHFLX \& $\mathrm{V}_{\text {sfc }}$

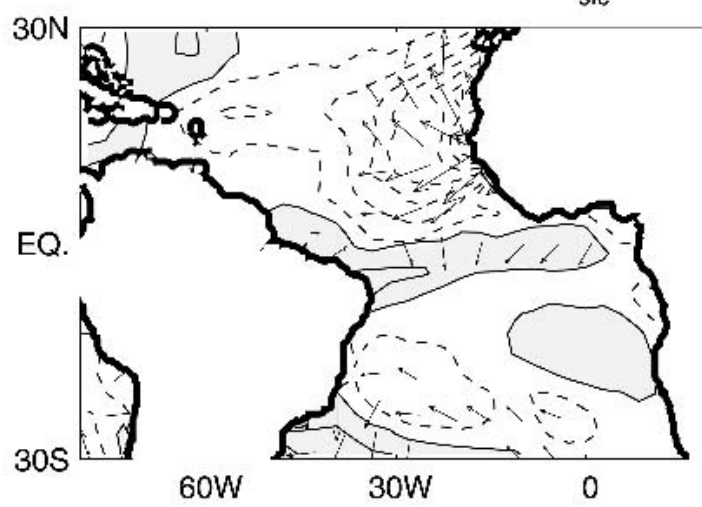

e. CTL-LPVE Feb LHFLX \& $V_{\text {sfc }}$

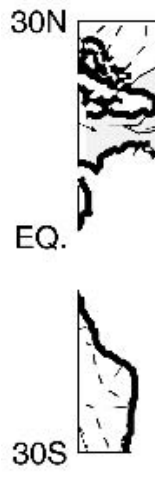

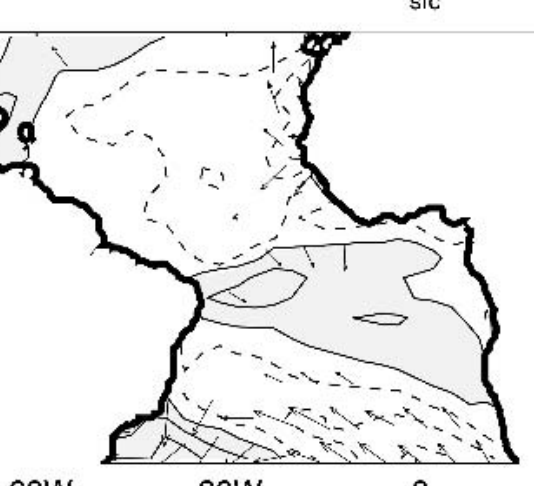

$60 \mathrm{~W}$ b. CpldCTL-CpldLPVE Dec LHFLX \& $V_{s f c}$

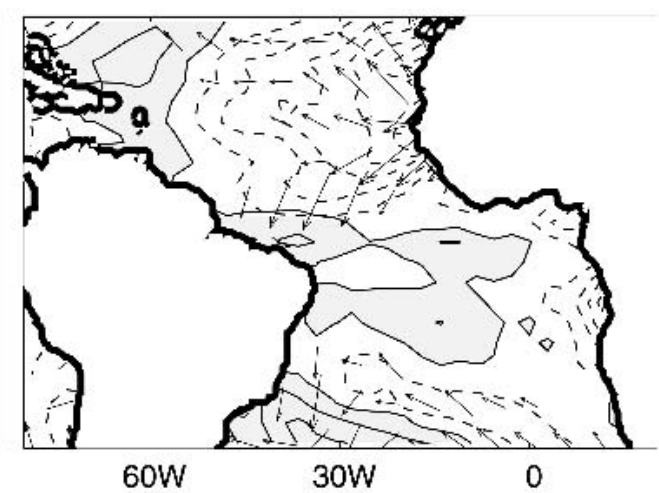

d. CpldCTL-CpldLPVE Jan LHFLX \& $V_{\text {sfc }}$

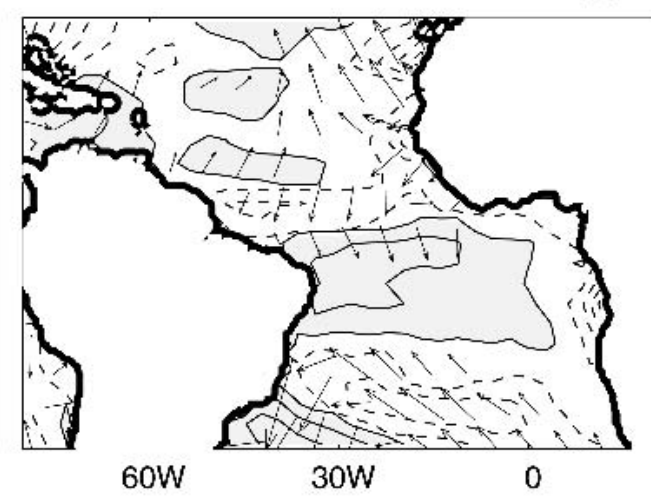

f. CpldCTL-CpldLPVE Feb LHFLX \& $V_{\text {sfc }}$

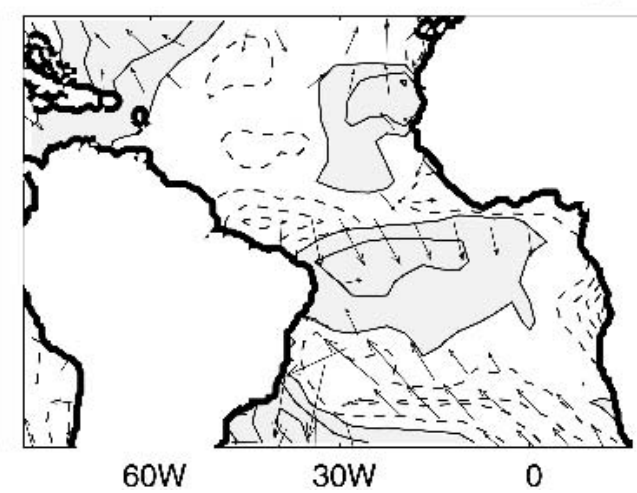

FIG. 9. The latent heat flux and surface wind response to the annual cycle of insolation over land in the case of (left) prescribed and (right) interactive SST. The contour interval is $20 \mathrm{~W} \mathrm{~m}^{-2}$, starting with \pm 10 ; dashed contours indicate negative values; and the shading indicates positive values larger than $10 \mathrm{~W} \mathrm{~m}^{-2}$. Only wind anomalies larger than $1.5 \mathrm{~m} \mathrm{~s}^{-1}$ are plotted. (a) Dec CTL - Dec LPVE, (b) Dec CpldCTL - Dec CpldLPVE, (c) Jan CTL - Jan LPVE, (d) Jan CpldCTL - Jan CpldLPVE, (e) Feb CTL - Feb LPVE, (f) Feb CpldCTL - Feb CpldLPVE.

of the ITCZ in our coupled experiment, is not crucial for either.

A complementary view of the development of the March displacement of the ITCZ is portrayed in Fig. 10. The top panel shows the annual cycle of the CpldCTL-CpldPVE anomalies in SAT over the Sahara; these anomalies are directly forced by insolation changes over land. The vertical gray line in Fig. 10a highlights the coldest SAT anomaly during December. (In the other panels of Fig. 10 the left side of the gray bar is December, while the right side extends to the time when the plotted anomalies reach their maximum amplitude; thus the width of the gray bar gives a visual estimate of the response time of each variable.) The 

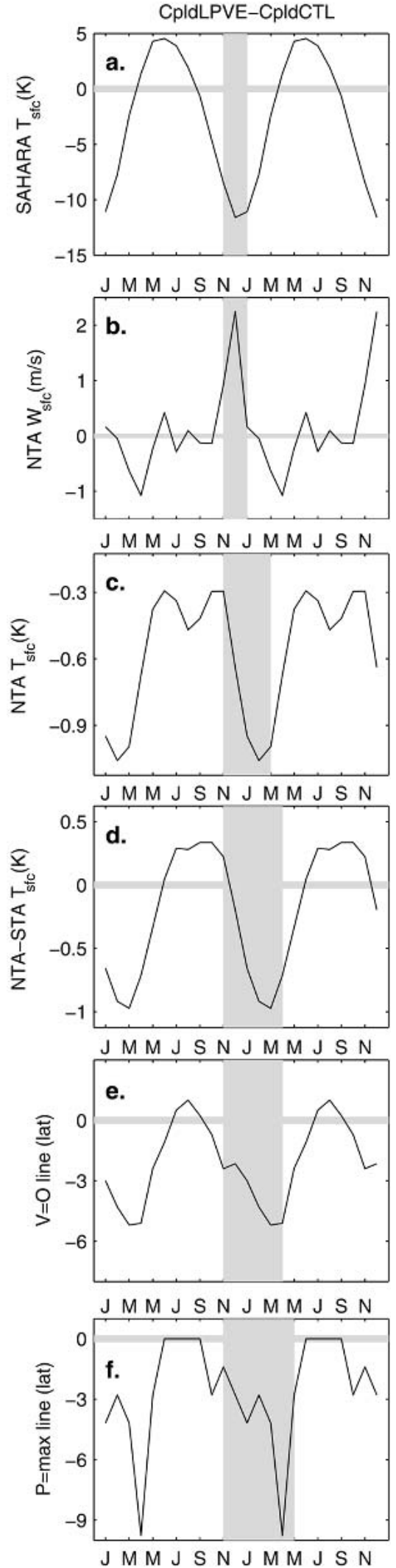

cold anomaly in the Sahara produces a high sea level pressure anomaly and easterly wind in the northern tropical Atlantic, strengthening the trades (Fig. 10b) and cooling the SST by evaporation. The maximum cooling in the northern tropical Atlantic is achieved in February (Fig. 10c) at which time virtually all of the cross-equatorial SST gradient is also established (Fig. 10d). The ITCZ responds to the SST gradient by shifting south, achieving the largest southward displacement in March (according to the confluence line, Fig. 10e) or April (according to precipitation maximum, Fig. 10f).

From the above discussion we infer that the timing of the maximum displacement of the ITCZ should be sensitive to the response time of the mixed layer, which in this simple model is just proportional to the mixed layer depth. We have performed a similar set of experiments in which the depth of the mixed layer is reduced to $1 \mathrm{~m}$ to make the ocean respond virtually instantaneously to the atmospheric forcing; in that case the maximum ITCZ displacement occurs in December (not shown).

We conclude this section with a caveat. In the above discussion we have disregarded the state of the midlatitudes. Obviously the insolation forcing has a large impact on the temperature of the northern midlatitude continents, and therefore on the midlatitude jets (but not on the midlatitude ocean temperature because those are prescribed in our model configuration). The fact that the changes in tropical SST and precipitation can plausibly be explained in terms of the insolationinduced temperature changes in the Sahara makes us confident that the midlatitude jets play a secondary role at best. Sensitivity experiments are under way in order to verify that this is indeed the case.

\section{b. The relative role of land precipitation and land surface temperature in inducing an ITCZ response}

Figures 11a and 11d show the difference CpldCTL CpldLPVE in the central Atlantic. As we have seen, the anomalies in SST meridional gradient and surface wind and the displacement of the ITCZ in boreal spring

$\leftarrow$

FIG. 10. The response to the annual cycle of insolation over land in the case of interactive SST (CpldCTL - CpldLPVE. (a) Surface air temperature in the Sahara. (b) Wind speed in the north tropical Atlantic. (c) SST in the north tropical Atlantic. (d) SST in the north tropical Atlantic and SST in the south tropical Atlantic. (e) Position of the Atlantic ITCZ as measured by the confluence line. (f) Position of the Atlantic ITCZ as measured by the maximum precipitation. The gray vertical line indicates the elapsed time between the time of the minimum surface temperature in the Sahara, Dec, and the time when the other indices reach an extrema. The wind response in the northern tropical Atlantic is instantaneous. The minimum SST in the tropical Atlantic is reached within 2 months, in Feb. The maxima in cross-equatorial SST gradient and in the displacement of the ITCZ is reached in Mar-Apr. 


\section{Land Insolation Effect CpldCTL-CpldLPVE}

a.

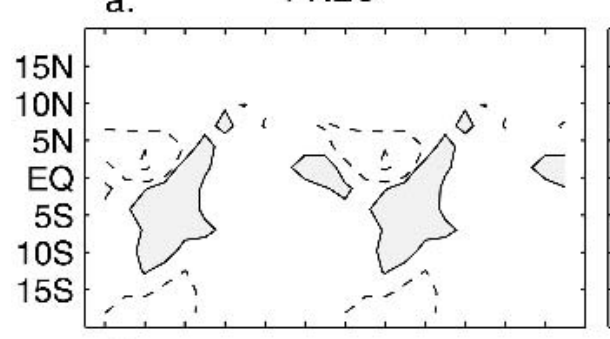

d.

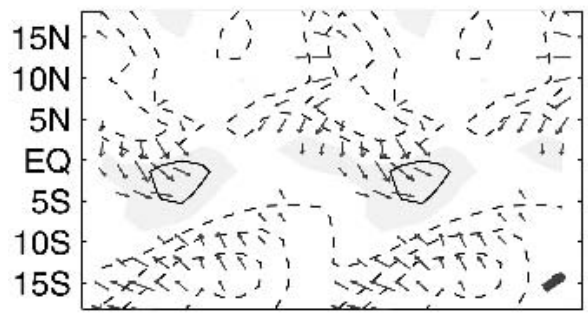

J M M J S J J M J S N

\section{Land $Q_{\text {cond }}$ Effect \\ CpldCTL-CpldPMQ}

b. PREC'

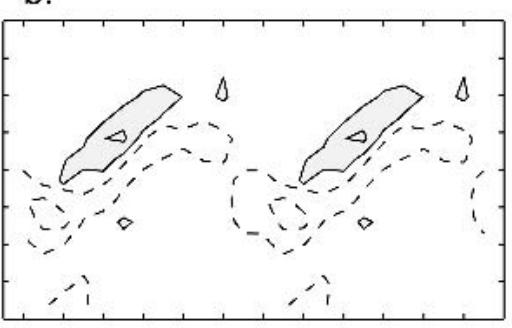

e.

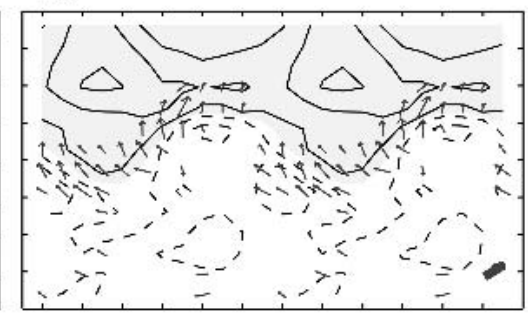

JMM J S N JMM J S N
Land Temperature Effect
CpldPMQ-CpldLPVE

c. PREC'

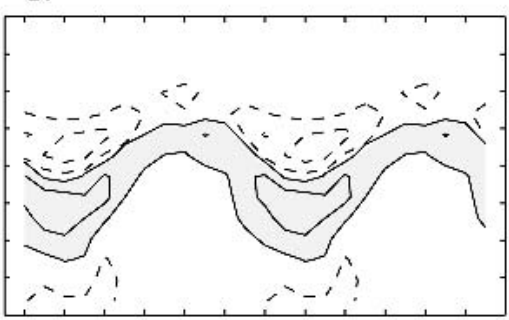

f.

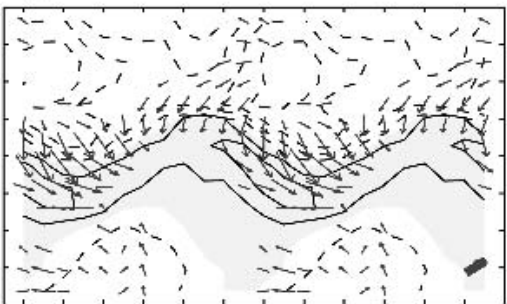

J M M J S N J M M J S N

FIG. 11. The annual cycle of the response of precipitation, SST, and surface wind in the central Atlantic ( $\left.30^{\circ} \mathrm{W}\right)$ to annually varying continental forcing as a function of month and latitude. (a), (d) CpldCTL - CpldLPVE: anomalies due to insolation over land. (b), (e) CpldCTL - CpldPMQ: anomalies due to precipitation over land. (c), (f) CpldPMQ - CpldLPVE: anomalies due to surface temperature over land. The contour interval for precipitation anomalies is $6 \mathrm{~mm} \mathrm{day}{ }^{-1}$, starting with \pm 3 ; dashed contours indicate negative values; and shading indicates positive values larger than $3 \mathrm{~mm} \mathrm{day}{ }^{-1}$. The contour interval for SST anomalies is $0.5^{\circ} \mathrm{C}$, the zero line is omitted, dashed contours indicate negative values, and shading indicates positive values. Only surface wind anomalies larger than $2 \mathrm{~m}$ $\mathrm{s}^{-1}$ are plotted; the bold arrows in the lower-right corner represent wind speed of $4 \mathrm{~m} \mathrm{~s}^{-1}$.

[March-May (MAM)] characterize the remote response over the Atlantic to seasonal changes in TOA insolation over land. Both land surface temperature and land precipitation changes due to the seasonal cycle in land insolation are concurrent with the oceanic anomalies portrayed here.

We can attempt to further decompose the effect of land on oceanic precipitation into the effect of elevated heating from land precipitation and the effect of land surface temperature by comparing the CpldLPVE and CpldPMQ experiments with the coupled control CpldCTL. In the CpldPMQ simulation, land insolation and ocean forcings (insolation and $Q$ flux) cycle through their climatology, whereas the elevated condensation heating associated with precipitation over Africa and South America is kept fixed at March value. Therefore, the difference plots CpldCTL - CpldPMQ (Figs. 11b,e) show the impact of elevated heating changes over Africa and South America (due to the annual cycle of insolation over land) on the climate of the central Atlantic. To the extent that changes in the midlatitudes climate can be neglected and that the effect of land surface temperature and land convective heating add up linearly, the difference CpldPMQ CpldLPVE (Figs. 11c,f) can be thought of as showing the maritime response to land surface temperature in Africa and South America. ${ }^{2}$

Figure 11 shows that the CpldCTL - CpldPVE precipitation and SST differences (Figs. 11a,d) are the result of large but opposite responses to changes in the elevated heating over the continents and to changes in the surface temperature of the continents, with surface temperature being the dominant forcing (cf. Figs. 11b with 11c and Figs. 11e with 11f). Land elevated heating induces a basinwide SST dipole anomaly, with a positive anomalous meridional gradient in SST and a northward shift of the ITCZ. Land surface temperature induces a negative anomalous meridional gradient of SST across the latitude of the ITCZ to which corresponds the southward movement of the ITCZ; outside of the

\footnotetext{
${ }^{2}$ Note that the land surface temperature changes do include the changes due to precipitation (and thus cloud cover and soil moisture): the land surface temperature changes are not those that insolation changes would produce in a dry model. We cannot separate out the total effect of continental precipitation changes. What we are attempting to do is to distinguish how much of the remote response to land climate is exerted though the free troposphere (i.e., in response to continental elevated heating) and how much through the boundary layer (i.e., in response to surface temperature).
} 
equatorial (ITCZ) region, land surface temperature produces negative anomalies. We remark that the ITCZ is consistently shifted north (south) throughout the year in response to forcing from land elevated heating (surface temperature) that changes sign over the course of the year.

There are two reasons for this. The principal reason is that the forcings have a nonzero annual mean. For example, the CpldLPVE is warmer in the mean than the CpldCTL, which means that the forcing from the CpldCTL - CpldLPVE land temperature during, say, June does not compensate for that during December (see Fig. 10); thus the annual mean response of the ITCZ is biased toward the December value. A secondary reason is that the feedbacks among the SST, the ITCZ, and the surface winds tend to maintain an original displacement of the ITCZ. Note that nonzero annual mean anomalies in SST are produced during the adjustment period (by definition, the annual mean heat fluxes are zero at equilibrium). Thus we cannot diagnose the mechanisms that gave rise to the aforementioned pattern of SST anomalies. Nevertheless, we speculate that the same mechanisms highlighted in sections 3 and $4 \mathrm{a}$ should be responsible for bringing the influence of land elevated heating and surface temperature, respectively, to the Atlantic Ocean.

\section{The ITCZ response to annually varying local forcings}

In this section we separate the role of the annual cycle in insolation over the ocean and of the annual cycle in the $Q$ flux (representing the ocean heat transport) in generating the annual cycle of the tropical Atlantic ITCZ. We show results from two additional experiments (see Table 2 and the appendix). In the CpldLPVE $\overline{Q f l u x}$ experiment, the only annually varying forcing is insolation over the ocean; insolation over land is fixed at the vernal equinox value and the $Q$ flux is prescribed to be the annual average of the $Q$ flux from the control integration. In the CpldLOPVE experiment, the $Q$ flux has an annual cycle; insolation is fixed at the vernal equinox value everywhere.

Figure 12 shows the annual cycle of precipitation, SST, and surface winds in the CpldLPVEQflux and CpldLOPVE simulations. Compared to the control (Fig. 6a), the annual cycle in the position of the ITCZ is reduced in both simulations (especially in the CpldLOPVE in which the annual variations derive entirely from the $Q$ flux). In both simulations, the equilibrium state has a year-round ITCZ in the north and a second maximum of precipitation in the southern Tropics that lasts only few months. Thus, these experiments would suggest that, while annual variations in both

\section{Varying Ocean Insolation Only a. PREC CPIdLPVEQ $\overline{Q \mid l u x}$}

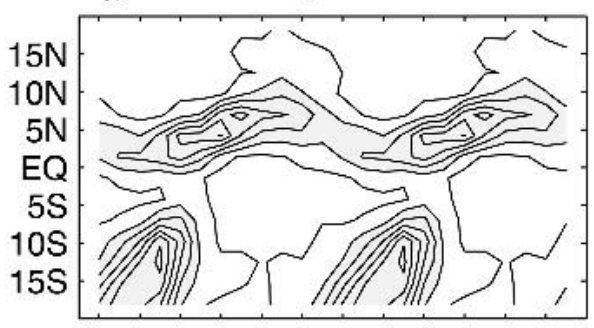

SST \& V CpldLPVEQflux

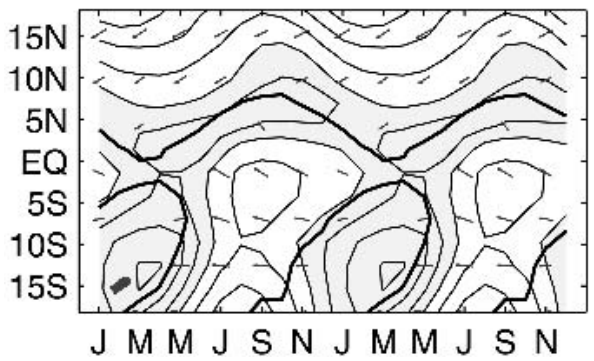

Varying Q-flux Only

b. PREC CPIdLOPVE

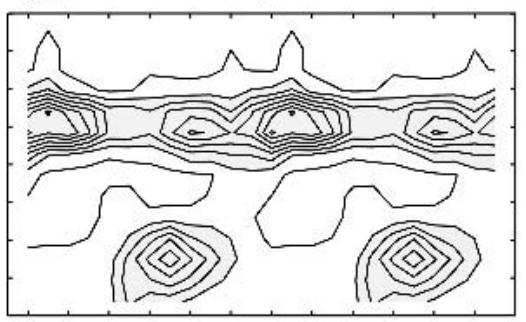

d. SST \& V CPIdLOPVE

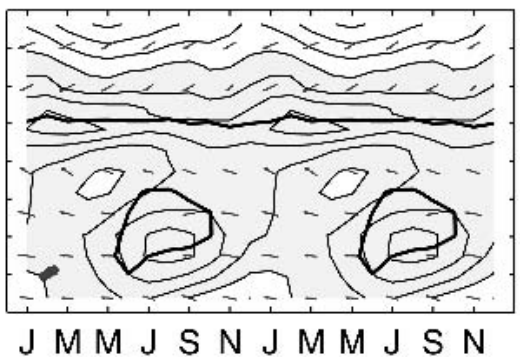

FIG. 12. The annual cycle of precipitation, SST, and surface wind in the central Atlantic $\left(30^{\circ} \mathrm{W}\right)$ in simulations with different annual forcings. (a), (c) CpldLPVE $\overline{\mathrm{Qflux}}$ : annual cycle due to local insolation. (b), (d) CpldLOPVE: annual cycle due only to the $Q$ flux. The contour interval for precipitation is $3 \mathrm{~mm}$ day $^{-1}$, starting with \pm 1.5 ; values larger than $4.5 \mathrm{~mm}$ day $^{-1}$ are shaded. The contour interval for SST is $1^{\circ} \mathrm{C}$; values larger than $27^{\circ} \mathrm{C}$ are shaded. Only surface wind vectors larger than $5 \mathrm{~m} \mathrm{~s}^{-1}$ are plotted; the bold arrow in the lower-left corners indicates a $10 \mathrm{~m} \mathrm{~s}^{-1}$ wind speed. 
ocean heat transport and insolation do generate a substantial annual cycle in the intensity of maritime precipitation, they have a weaker effect over the annual meridional march of the ITCZ.

Yet, some caution in the interpretation of these results needs to be exercized. One caveat derives from the fact that the annually averaged insolation is different in the two simulations. In particular the northern Tropics receive in the annual mean more insolation in perpetual vernal equinox conditions then they do for climatological insolation. This additional insolation contributes to the pronounced warming at about $7^{\circ} \mathrm{N}$ seen in Fig. $12 \mathrm{~d}$.

A second consideration we wish to emphasize is that the above results are only valid in the context of AGCM+SOM experiments. While it is appropriate to refer to the $Q$-flux forcing as a local forcing in the context of $\mathrm{AGCM}+\mathrm{SOM}$ experiments, in reality the ocean heat transport that we parameterize with the $Q$ flux is the result of ocean dynamics that is, in principle, the result of both local and remote forcings. Sorting out the cause of annual variations in ocean heat transport requires a dynamical ocean, and cannot be done in our simpler model configuration. Furthermore, the SOM uses a constant, uniform mixed layer depth of $50 \mathrm{~m}$. In the real world, the depth of the mixed layer varies in space and time, introducing another modulation in the response of the ocean to surface fluxes. The depth of the mixed layer is determined by the the strength of the wind and by advective processes in the ocean, and thus depends in a nontrivial way on both local and remote forcings. Finally, although we have interpreted the $Q$ flux as a parameterization of the ocean heat transport convergence, it also corrects for model biases, which might present a nontrivial annual cycle.

\section{Summary and discussion}

We have investigated how changes in surface temperature and precipitation over South America and Africa affect the Atlantic ITCZ. We used the Community Climate Model version 3 (CCM3) AGCM, coupled in the tropical Atlantic to a slab ocean model (SOM) of uniform and constant depth. Thus, the tropical Atlantic SST can respond to radiative and turbulent fluxes but not to the dynamical consequences of wind stress. The effect of ocean dynamics is parameterized by a flux correction (referred to as the $Q$ flux).

In this model configuration the climate over the tropical Atlantic Ocean is forced locally by the insolation overhead and the $Q$ flux and remotely by the circulation driven by surface temperature and precipitation over land. We have performed experiments in which these different forcings were applied independently to the CCM3+SOM model (see Table 2 for a complete list of the coupled experiments presented in this paper). Comparison of the annual cycle in these experiments provides us with an estimate of how im- portant each forcing is in determining the annual cycle of the Atlantic ITCZ.

The main conclusion of this study is that variations in precipitation and temperature over the continents are as important as variations in insolation over the ocean and in ocean heat transport convergence in forcing the annual march of the Atlantic ITCZ observed in the control simulation.

In sections 4 and 5 we have shown that the simulated control climatology of the Atlantic ITCZ is the result of a balance between the annual variations of local insolation, ocean heat transport, continental surface temperature, and continental precipitation, and that no single forcing is dominant. The annual variations in insolation over the ocean and in ocean heat transport modulate the intensity of precipitation in the tropical Atlantic, both north and south of the equator, but neither is sufficient to force the cross-equatorial migration of the ITCZ seen during boreal spring in the control simulation. In contrast, the annual variations in terrestrial forcings (continental surface temperature and precipitation) affect the position of the ITCZ more than its intensity, with the forcing due to continental precipitation (elevated condensation heating) partially counteracting the dominant effect of the continental surface temperature forcing.

Figure 13 offers a succinct summary of our results. It shows the amplitude and phase of the annual harmonic of precipitation and surface temperature in response to annually varying insolation and ocean heat transport (CpldCTL; Figs. 13a,b), land insolation only (CpldCTL-CpldLPVE; Figs. 13c,d), ocean forcings only (CpldLPVE; Figs. 13e,f), ocean insolation only (CpldLPVEQflux; Figs. 13g,h), and $Q$ flux only (CpldLOPVE; Figs. 13i,l). The length of each vector gives a measure of the amplitude of the annual cycle (more precisely, it represents the amplitude of the annual harmonic of the climatology) at that location, and the direction represents its phase, with an arrow pointing upward indicating a maximum in January, and time progressing clockwise.

A comparison of the annual harmonic of temperature and precipitation in the control run is interesting in its own right: it shows that the largest amplitude in the annual variations of oceanic precipitation in this model is achieved in the western equatorial basin where the annual harmonic of SST is negligible. SST has a much larger annual harmonic in the eastern equatorial region in the Gulf of Guinea. This local "decoupling" of the SST and the ITCZ is even more apparent in the annual harmonic simulated in response to the annual cycle of insolation over land: The ITCZ response is very strong (and strikingly similar to the control annual harmonic in the equatorial region), while the SST response is weak. The remotely forced annual harmonic of the ITCZ is the result of a cancellation between the response to continental precipitation (Fig. 13m) and continental surface temperature (Fig. 13o). The locally 

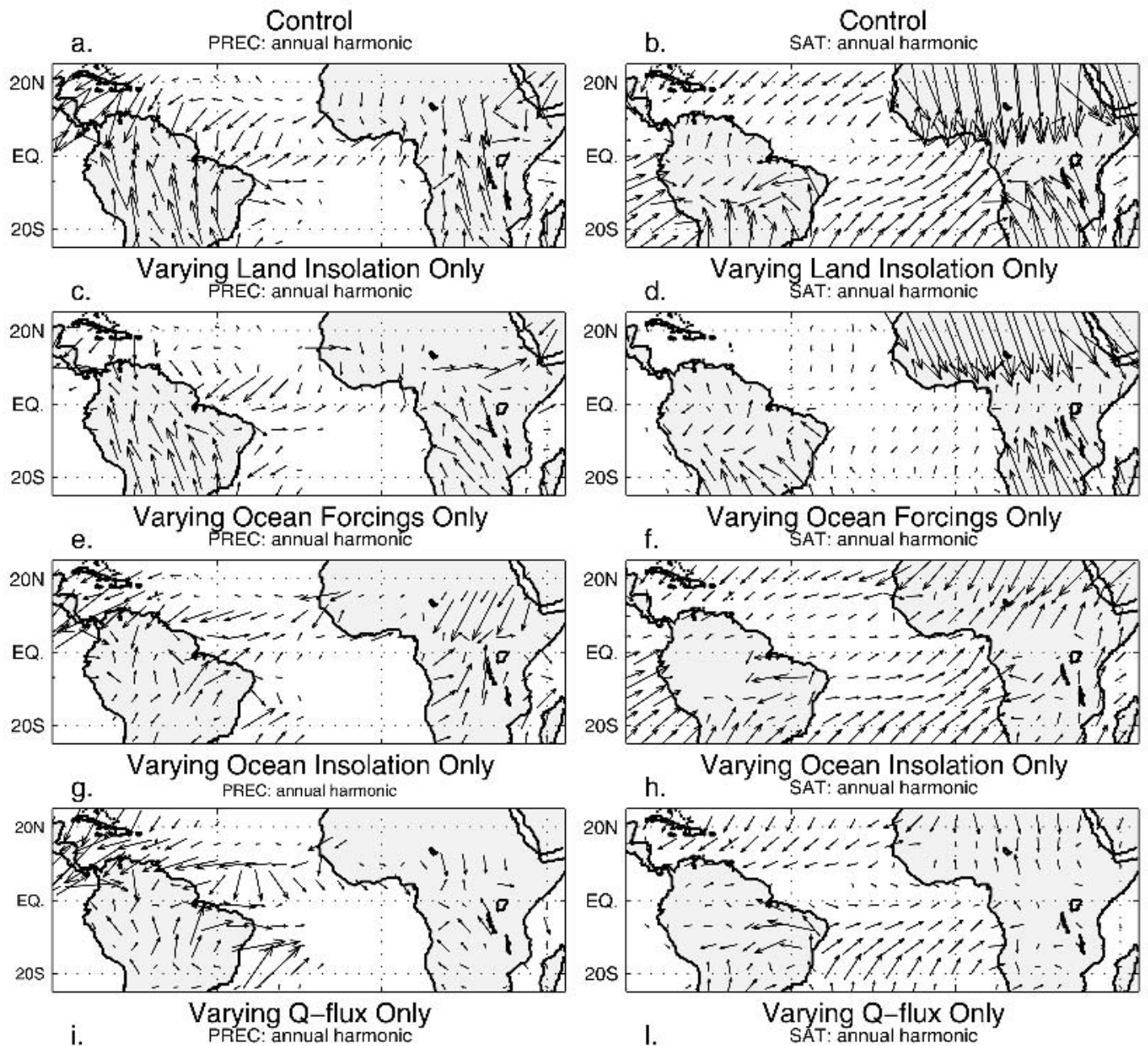

$\mathrm{h}$
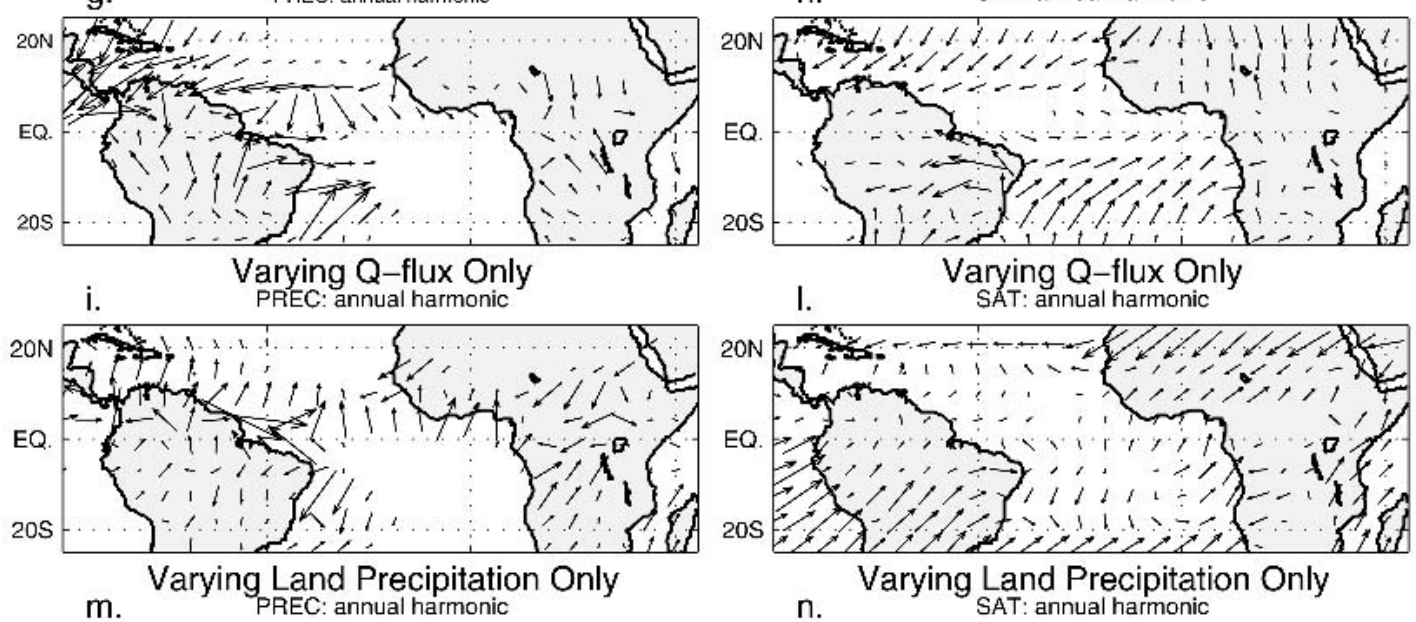

m. Varying Land Precipitation
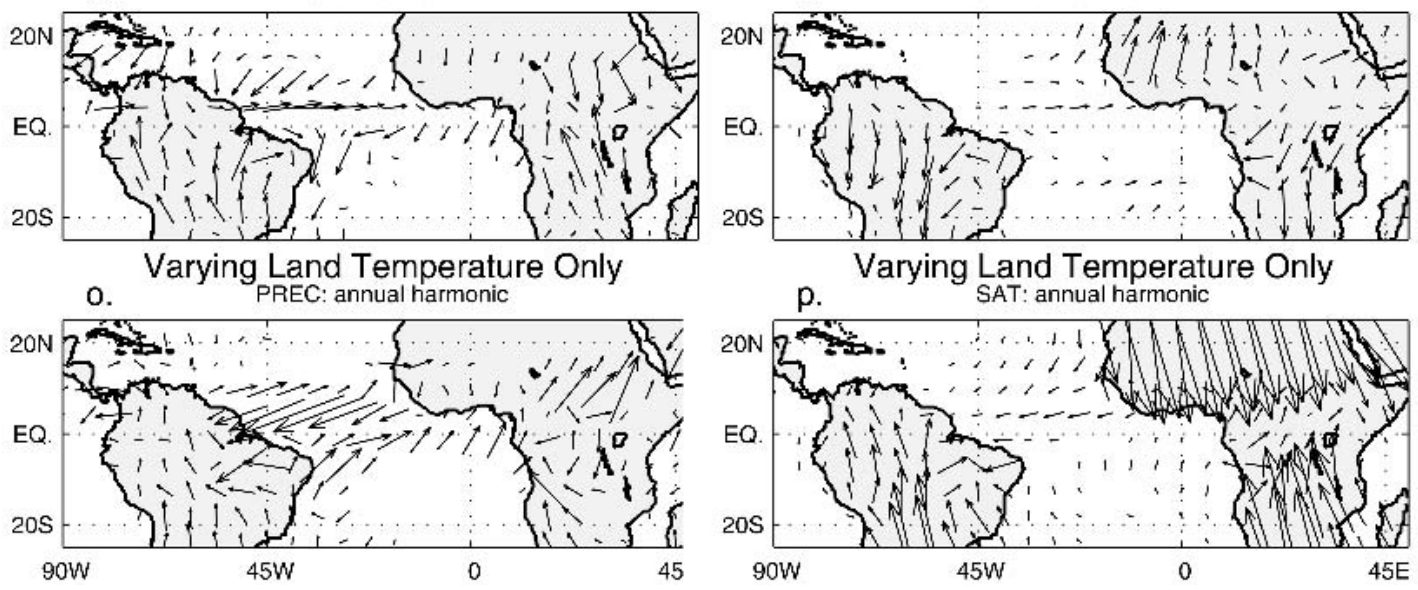
forced annual harmonic in oceanic precipitation (i.e., that forced by insolation over the ocean and by the $Q$ flux) is of the same amplitude of that forced remotely (cf. Figs. 13c and 13e) and is the result of partial cancellation between the effect of the insolation and the $Q$ flux (cf. Figs. 13g and 13i).

The annual harmonic of SST appears to be mainly a response to local insolation, although variations in $Q$ flux are also important, especially in the Gulf of Guinea. At first glance, this result seems at odds with Carton and Zhou (1997), who conclude that insolation had little effect between $5^{\circ} \mathrm{S}$ and $10^{\circ} \mathrm{N}$. That they came to a different conclusion may simply be due to the differences in the experimental design. Carton and Zhou (1997) use an uncoupled ocean model, which they drive with either the annual cycle or the annual mean of the observed surface heat fluxes and winds. Thus, their experiment can only capture the uncoupled response of SST to the annual cycle of insolation. However, in the equatorial Atlantic wind, precipitation, and SST are governed by strongly coupled dynamics.

Our conclusion about the role of ocean heat transport in determining the annual cycle of SST agrees with that of Carton and Zhou (1997) qualitatively, but not quantitatively. This might be a consequence of the fact that in our $Q$-flux-only experiment there are significant changes to the surface wind-and thus surface heat flux-due to atmosphere-ocean coupling. Moreover, extrapolating our conclusion on the relative role of annual variations in the $Q$ flux in generating the annual cycle of SST to the role of ocean dynamics is probably not warranted: the $Q$ flux also corrects for the choice of a uniform constant mixed layer depth, and is contaminated by biases in the atmospheric fluxes.

In regard to the $Q$ flux we also note that, in this model configuration, the $Q$ flux can be interpreted as a local forcing, but in reality the ocean heat transport convergence contains the effect of horizontal advection by ocean currents, upwelling, and the deepening and shoaling of the mixed layer depth. Thus, it is the product of local and remote forcings alike. In particular, Mitchell and Wallace (1992) in an observational study and $\mathrm{Li}$ and Philander (1997) in a modeling study have suggested that the southerly wind in the (land driven) African monsoon is the main driver for the dynamics of the Atlantic cold tongue. A recognition of the total effect of the continents on the oceanic climate requires the use of a dynamical ocean model and is beyond the scope of this study.
We conclude with a brief remark on the implications of this study. We have shown that variations in the African climate easily trigger a coupled response in the surface wind, the ITCZ, and the cross-equatorial SST gradient in the tropical Atlantic, whose net effect is the meridional displacement of the ITCZ. Thus, good simulation of tropical Atlantic climate in interactive oceanatmosphere models will need good representation of processes over the neighboring continents and their connections to the oceanic sector.

As an interesting aside, we not that our results on the influence of the Sahara on the Atlantic suggest that paleoclimate changes like the mid-Holocene greening of the Sahara (with the accompanying changes in surface temperature and precipitation) should be traceable in paleo records of the ITCZ position in the equatorial Atlantic. Furthermore, our results suggest that-insofar as the mechanisms responsible for interannual variability are indeed similar to those responsible for the annual cycle as it has been claimed (Hastenrath 1984) variability in, say, African climate might contribute to the variability of the ITCZ.

Acknowledgments. The authors wish to thank an anonymous reviewer, Mike Wallace, Dennis Hartmann, and especially John Chiang for their insightful suggestions and editorial comments. This publication is supported by a grant to the Joint Institute for the Study of the Atmosphere and Ocean (JISAO) under NOAA Cooperative Agreement NA17RJ1232.

\section{APPENDIX}

\section{Experiment Summary}

\section{a. Uncoupled simulations}

- CTL: The control simulation is run with prescribed annual cycle of SST and top-of-atmosphere (TOA) insolation.

- PMS: The perpetual March SST simulation has SST fixed at March value, but climatological TOA insolation. The monthly condensational heating over South America and Africa (hereafter referred to as $Q)$ is saved and used to force other simulations.

- PM: The perpetual March simulation has March SST and 21 March equinox insolation. Thus PM will be

FIG. 13. Harmonic dial of the annual cycle of (left column) precipitation and (right column) surface air temperature in (a) and (b) CpldCTL; (c) and (d) CpldCTL - CpldLPVE; (e) and (f) CpldLPVE; (g) and (h) CpldLPVE $\overline{Q f l u x}$; (i) and (l) CpldLOPVE; (m) and (n) CpldCTL-CpldPMQ; (o) and (p) CpldPMQ-CpldLPVE. The direction of the arrows indicates the max in the annual harmonic, with Jan pointing upward and time increasing clockwise. The length of the arrows indicates the amplitude of the annual harmonic. The smallest arrow in the precipitation plots indicates an amplitude of $0.5 \mathrm{~mm}$ day $^{-1}$. The smallest arrow in the surface air temperature plots indicates an amplitude of $0.25^{\circ} \mathrm{C}$. 
similar, but not identical, to March conditions in CTL and PMS.

- PMJQ: This simulation is a perpetual March, like PM, but $Q$ is prescribed to its June value. In short, PMJQ is PM with heating added as in Fig. 1.

- LPVE: The land perpetual vernal equinox simulation has 21 March TOA insolation over land and climatological TOA insolation over the ocean. Because the SST is prescribed, LPVE is virtually identical to PVE in BBS1 in which insolation is fixed over both the land and the ocean. Because the precipitation over land is largely determined by insolation, the condensational heating over land is very similar in LPVE, PM, and March conditions in CTL.

\section{b. Coupled simulations}

- CpldCTL: The control simulation is run with prescribed annual cycle of TOA insolation and annual cycle of $Q$ flux. (The $Q$ flux, that is, the flux correction required by the slab ocean model to reproduce the observed SST climatology, is determined using the surface heat fluxes from CTL.)

- CpldPMQ: The perpetual March heating is like CpldCTL, but $Q$ is prescribed to its March value (from PMS).

- CpldPJQ: The perpetual June $Q$ is like CpldCTL but with prescribed June $Q$. In short, CpldPJQ is CpldPMQ with added heating as in Fig. 1.

- CpldLPVE: The coupled land perpetual vernal equinox simulation has 21 March TOA insolation over land and climatological insolation and $Q$-flux forcing the ocean. To the extent that precipitation over land is largely determined by insolation, the condensational heating over land corresponds to March conditions.

- CpldLPVE $\overline{Q f l u x}$ : This has 21 March TOA insolation over land, climatological insolation over the ocean, and annual-mean $Q$ flux. To the extent that precipitation over land is largely determined by insolation, the condensational heating over land corresponds to March conditions.

- CpldLOPVE: This is forced by 21 March TOA insolation everywhere, over both land and ocean, and by the annual cycle of the $Q$ flux. To the extent that precipitation over land is largely determined by insolation, the condensational heating over land corresponds to March conditions.

\section{REFERENCES}

Biasutti, M., D. S. Battisti, and E. S. Sarachik, 2003: The annual cycle over the tropical Atlantic, South America, and Africa. J. Climate, 16, 2491-2508.
_ and 2004: Mechanisms controlling the annual cycle of precipitation in the tropical Atlantic sector in an atmospheric GCM. J. Climate, 17, 4708-4723.

Carton, J. A., and Z. Zhou, 1997: Annual cycle of sea surface temperature in the tropical Atlantic Ocean. J. Geophys. Res. 102 (C13), 27 813-27 824.

Chang, P., L. Ji, and H. Li, 1997: A decadal climate variation in the tropical Atlantic Ocean from thermodynamic air-sea interactions. Nature, 385, 516-518.

— R. Saravanan, L. Ji, and G. C. Hegerl, 2000: The effect of local sea surface temperatures on atmospheric circulation over the tropical Atlantic sector. J. Climate, 13, 2195-2216.

Chiang, J. C. H., S. E. Zebiak, and M. A. Cane, 2001: Relative roles of elevated heating and surface temperature gradients in driving anomalous surface winds over tropical oceans. $J$. Atmos. Sci., 58, 1371-1394.

- M. Biasutti, and D. S. Battisti, 2003: Sensitivity of the Atlantic ITCZ to Last Glacial Maximum boundary conditions. Paleoceanography, 18, 1094, doi:10.1029/2003PA000916.

Davey, M. K., and Coauthors, 2002: STOIC: A study of coupled model climatology and variability in tropical ocean regions. Climate Dyn., 18, 403-420.

Gill, A. E., 1980: Some simple solutions for heat-induced tropical circulation. Quart. J. Roy. Meteor. Soc., 106, 447-462.

Hack, J., J. Kiehl, and J. Hurrell, 1998: The hydrologic and thermodynamic characteristics of the NCAR CCM3. J. Climate, 11, 1207-1236.

Hastenrath, S., 1984: Interannual variability and the annual cycle: Mechanisms of circulation and climate in the tropical Atlantic sector. Mon. Wea. Rev., 112, 1097-1107.

_ , and L. Greischar, 1993: Further work on the prediction of northeast Brazil rainfall anomalies. J. Climate, 6, 743-758.

Kiehl, J. T., J. J. Hack, G. B. Bonan, B. A. Boville, D. L. Williamson, and P. J. Rasch, 1998: The National Center for Atmospheric Research Community Climate Model: CCM3. J. Climate, 11, 1131-1150.

Li, T., and S. G. H. Philander, 1997: On the seasonal cycle of the equatorial Atlantic. J. Climate, 10, 813-817.

Lindzen, R. S., and S. Nigam, 1987: On the role of sea surface temperature gradients in forcing low-level winds and convergence in the Tropics. J. Atmos. Sci., 44, 2418-2436.

McGauley, M., C. Zhang, and N. A. Bond, 2004: Large-scale characteristics of the atmospheric boundary layer in the eastern Pacific cold tongue-ITCZ region. J. Climate, 17, 3907-3920.

Mitchell, T. P., and J. M. Wallace, 1992: The annual cycle in equatorial convection and sea surface temperature. J. Climate, 5, 1140-1156.

Saravanan, R., and P. Chang, 1999: Oceanic mixed layer feedback and tropical Atlantic variability. Geophys. Res. Lett., 26, 3629-3632.

—, and - 2000: Interaction between tropical Atlantic variability and El Niño-Southern Oscillation. J. Climate, 13, 2177-2194.

Seager, R., Y. Kushnir, P. Chang, N. Naik, J. Miller, and W. Hazeleger, 2001: Looking for the role of the ocean in the tropical Atlantic decadal climate variability. J. Climate, 14, 638-655.

Xie, S. P., and S. G. H. Philander, 1994: A coupled oceanatmosphere model of relevance to the ITCZ in the eastern Pacific. Tellus, 46A, 340-350. 